Review

\title{
Therapeutic Targeting of Hyaluronan in the Tumor Stroma
}

\author{
Anne Kultti ${ }^{1, *}$, Xiaoming $\mathrm{Li}^{2}$, Ping Jiang ${ }^{2}$, Curtis B. Thompson ${ }^{2}$, Gregory I. Frost ${ }^{3}$ and \\ H. Michael Shepard ${ }^{1}$
}

1 Department of Research, Halozyme Therapeutics, 11388 Sorrento Valley Road, San Diego, CA 92121, USA; E-Mail: mshepard@halozyme.com (H.M.S.)

2 Department of Pharmacology and Safety Assessment, Halozyme Therapeutics, 11388 Sorrento Valley Road, San Diego, CA 92121, USA; E-Mails: xli@halozyme.com (X.L.); pjiang@halozyme.com (P.J.); cthompson@halozyme.com (C.B.T.)

3 Department of General and Administrative, Halozyme Therapeutics, 11388 Sorrento Valley Road, San Diego, CA 92121, USA; E-Mail: gfrost@halozyme.com (G.I.F.)

* Author to whom correspondence should be addressed; E-Mail: akultti@halozyme.com; Tel.: +1-858-704-8339; Fax: +1-858-704-8311.

Received: 25 June 2012; in revised form: 28 August 2012 / Accepted: 31 August 2012 / Published: 6 September 2012

\begin{abstract}
The tumor stroma, consisting of non-malignant cells and the extracellular matrix, undergoes significant quantitative and qualitative changes throughout malignant transformation and tumor progression. With increasing recognition of the role of the tumor microenvironment in disease progression, stromal components of the tumor have become attractive targets for therapeutic intervention. Stromal accumulation of the glycosaminoglycan hyaluronan occurs in many tumor types and is frequently associated with a negative disease prognosis. Hyaluronan interacts with other extracellular molecules as well as cellular receptors to form a complex interaction network influencing physicochemical properties, signal transduction, and biological behavior of cancer cells. In preclinical animal models, enzymatic removal of hyaluronan is associated with remodeling of the tumor stroma, reduction of tumor interstitial fluid pressure, expansion of tumor blood vessels and facilitated delivery of chemotherapy. This leads to inhibition of tumor growth and increased survival. Current evidence shows that abnormal accumulation of hyaluronan may be an important stromal target for cancer therapy. In this review we highlight the role of hyaluronan and hyaluronan-mediated interactions in cancer, and discuss historical and recent data on hyaluronidase-based therapies and the effect of hyaluronan removal on tumor growth.
\end{abstract}


Keywords: cancer; tumor stroma; hyaluronan; hyaluronidase; PEGPH20

Abbreviation: BRCA1, breast cancer 1; BSA, bovine serum albumin; CD44, cluster of differentiation 44; Coll $\alpha 1$, collagen, type 1, alpha 1; Col5 $\alpha 1$, collagen, type 5, alpha 1; CS, chondroitin sulfate; DS, dermatan sulfate; ECM, extracellular matrix; EGF, epidermal growth factor; ERK1/2, extracellular signal-regulated kinase 1/2; ERM, ezrin-radixin-moesin; FAK, focal adhesion kinase; GFP, green fluorescent protein; HABP, hyaluronan binding protein; GPI, glycosylphosphatidylinositol; GTPase, guanosine triphosphatase; HA, hyaluronan; HAS, hyaluronan synthase; hdf, heart defect; HER, human epidermal growth factor receptor; HS, heparan sulfate; HYAL, hyaluronidase; HYALP-1, hyaluronidase pseudogene 1; I $\alpha \mathrm{I}$, inter- $\alpha$-inhibitor; KPC, LSL-Kras ${ }^{\mathrm{G} 12 \mathrm{D} /+}$; LSL-Trp53 ${ }^{\mathrm{R} 172 \mathrm{H} /+}$; Pdx-1-Cre; MAPK, mitogen-activated protein kinase; NSCLC, non-small cell lung cancer; PDA, pancreatic ductal adenocarcinoma; PDGFR, platelet-derived growth factor receptor; PEG, polyethylene glycol; PEGPH20, pegylated human recombinant PH20 hyaluronidase enzyme; PLN, para-aortic lymph node; PI3K, phosphoinositide 3-kinase; RHAMM, receptor for hyaluronan-mediated motility; rHuPH20, recombinant human PH20 hyaluronidase; RTK, receptor tyrosine kinase; SEM, standard error of the mean; SHAP, serum-derived hyaluronan-associated protein; SPAM-1, sperm adhesion molecule-1; Stab2, stabilin-2; tIFP, tumor interstitial fluid pressure; TGF $\beta$, transforming growth factor beta receptor; TGI, tumor growth inhibition; TLR, toll-like receptor; TNC, tenascin-C; TNF- $\alpha$, tumor necrosis factor-alpha; TSG-6, tumor necrosis factor-inducible gene 6 protein; UDP, uridine 5' diphosphate; VEGF-A, vascular endothelial growth factor A.

\section{Introduction-The Tumor Stroma}

A solid tumor is a highly specialized organ-like structure in disequilibrium with the rest of the body. For the purpose of this review, we have conceptually divided the tumor into two functional parts, malignant cells and the tumor stroma, and will focus this review on the role of the glycosaminoglycan hyaluronan (HA) in the interaction between the tumor stroma and the associated malignant cells. We will also discuss recent preclinical evidence supporting therapeutic targeting of tumor stroma HA via depletion of HA.

The tumor stroma, a supportive framework for malignant cells, consists of various non-malignant cell types and the associated tumor extracellular matrix (ECM), with its multitude of embedded growth factors and protumorigenic elements [1]. Specialized cell types found in the tumor stroma include fibroblasts, myofibroblasts, endothelial cells, pericytes, tumor-associated macrophages and varying numbers of other immune cells [2,3]. More than just a passive bystander to disease progression, the tumor stoma undergoes massive remodeling in response to signals derived from both malignant and host cells, evolving from a barrier to tumor growth to an active contributor of malignant progression [3].

While the communication between the malignant cells and stromal cells may help drive the chronicity of the malignancy, it also makes the tumor stroma an emerging source of targets for the treatment of malignant disease. Indeed, a number of candidate cancer therapeutics have been identified from studies focused on malignant cell:stromal cell interactions (see recent reviews [4,5]). Probably the best known cancer therapeutic to come from these studies is trastuzumab (Herceptin ${ }^{\circledR}$ ), an antibody 
inhibitor of the $\mathrm{p} 185^{\mathrm{HER} 2}$ receptor tyrosine kinase (RTK). It was discovered in a screen for monoclonal antibodies that reversed the macrophage-resistant phenotype of tumor cells, making them more sensitive to killing by macrophage-elaborated tumor necrosis factor-alpha (TNF- $\alpha$ ) [6]. Additional examples of therapeutic targets identified from malignant cell:stromal cell interaction studies include: bevacizumab, which inhibits vascular endothelial growth factor A (VEGF-A), an angiogenesis-related growth factor, preventing stromal vessel formation [7]; vismodegib, a small molecule inhibitor of the hedgehog pathway which targets both tumor stroma and cancer stem cells and has shown very promising results in preclinical studies, and which is currently being tested in several clinical trials of pancreatic adenocarcinoma (PDA) [8]; and TH-302, a hypoxia-activated prodrug which has also been shown to increase the antitumor activity of a broad range of conventional chemotherapy agents in human xenograft models and for which clinical testing is ongoing [9,10]. Similarly, and the focus of this review, the accumulation of HA in the tumor stroma is now recognized as a stromal target for the experimental treatment of malignancies [11-14], and is the subject of ongoing clinical investigations using an intravenously delivered HA-depleting enzyme, specifically a pegylated human recombinant PH20 hyaluronidase (PEGPH20) [15,16].

\section{Hyaluronan (HA)}

HA, a large, unbranched, non-sulfated glycosaminoglycan composed of repeating disaccharide units of D-glucuronic acid and $\mathrm{N}$-acetylglucosamine, is a major constituent of the ECM of most tissues. While simple in composition, HA polymers can reach up to 25,000 disaccharide units, with molecular weights in the $10^{7}$ Dalton range, and are capable of organizing into complex structures and interacting directly or indirectly with many components of the ECM. The enzymes that produce HA are hyaluronan synthases (HAS). There are three HA synthases (HAS1-3) in mammalian cells, each of which possesses the two glycosyltransferase activities responsible for the transfer of $N$-acetylglucosamine and D-glucuronic acid from their uridine 5'-diphosphate (UDP) precursors to the growing HA chains [17]. The three isoforms are independently regulated and are thought to produce distinct molecular weight forms of HA [18-22]. HAS2 deficiency has been shown to be embryonic lethal, whereas the other synthases may play more subtle roles in development [23,24]. Unlike most other glycosaminoglycans, which are processed and extensively modified in the Golgi, HA is synthesized at the inner face of the plasma membrane and secreted as a linear undecorated polysaccharide directly into the extracellular space. The kinetics controlling HA synthesis in vivo are largely unknown but are likely dependent on available cytosolic UDP-monosaccharide concentrations [25]. In malignancy, HAS activity generates large intact linear molecules of HA that are either rapidly incorporated into the ECM surrounding the tumor cells, or retained at the cell surface through HA binding receptors and interacting glycoproteins and proteoglycans. HA may also be tethered to the cell surface by interactions with HAS proteins themselves [26-28]. Transgenic studies have shown that while their expression is not itself transforming, HA synthases can cooperate with oncogenes to promote tumor growth and desmoplastic transformation of the tumor stroma [29].

HA degradation is carried out by a family of enzymes called hyaluronidases (HYAL). Genomic analysis reveals that mammals possess multiple hyaluronidase genes, including HYAL-1 through HYAL-5, PH20, and in humans a pseudogene designated HYALP-1 [30]. None of the degradative 
hyaluronidase enzymes have a lethal phenotype [31-36]. HYAL-5 appears to have enzymatic activity redundant to $\mathrm{PH} 20$, except for a difference in $\mathrm{pH}$ optima, and is not expressed in humans. $\mathrm{PH} 20$ is encoded by the sperm adhesion molecule-1 (SPAM-1) gene, and has been studied mostly in the testes where it is localized to the heads of mature sperm. An engineered therapeutic hyaluronidase, a human recombinant form of $\mathrm{PH} 20$ ( $\mathrm{rHuPH} 20$ ) has been developed, and is approved for use in the local dispersion of co-injected drugs, and is currently being tested in clinical trials to facilitate the subcutaneous delivery of macromolecules [37-39].

\section{The Role of Hyaluronan in the Tumor Stroma}

Due to its high negative charge, HA is capable of coordinating up to 10,000 times its weight in water, which contributes to its ability to increase interstitial fluid pressure at those sites where it accumulates [40]. Overall, about 25-30\% of human tumors overexpress HA, and of special interest for this review, up to $87 \%$ of PDAs express high levels of this glycosaminoglycan (Figure 1) [11]. In particular, in tumors that originate from epithelia, which normally express low levels of HA (e.g., breast, prostate, bladder and colorectal cancer), cancer cell-associated HA accumulation is a negative prognostic indicator for cancer patients [41]. The aberrant accumulation of HA in tumors likely occurs via dysregulation of HA synthases and hyaluronidases during disease progression [42,43]. Indeed, it has been suggested that different HAS isoforms might be expressed in different stages of tumor growth to maximize survival of the cancer cells [43]. Whether the constant degradation and resynthesis of HA in tumor foci characterized by high levels of accumulation of this glycosaminoglycan may contribute to the state of immune activation within a tumor is the subject on ongoing research [44].

Figure 1. HA accumulation occurs in $87 \%$ of pancreatic cancer, and $25-30 \%$ of solid tumors overall. (a) HA was detected in samples by immunohistochemistry using biotinylated HA binding protein as described in Jacobetz et al. [11]. A score of $\mathrm{HA}^{+3}$ corresponds to $>25 \%$ strong positive stain area as compared to the total stain per field. PC3 prostate cancer xenografts were used as a positive control to determine the threshold for positive pixel quantity. Specificity of the staining was confirmed by pretreating a section of same sample with PH20 hyaluronidase in parallel with the test section; (b) The percentage of $\mathrm{HA}^{+3}$ tumors in different tumor types [11].

a
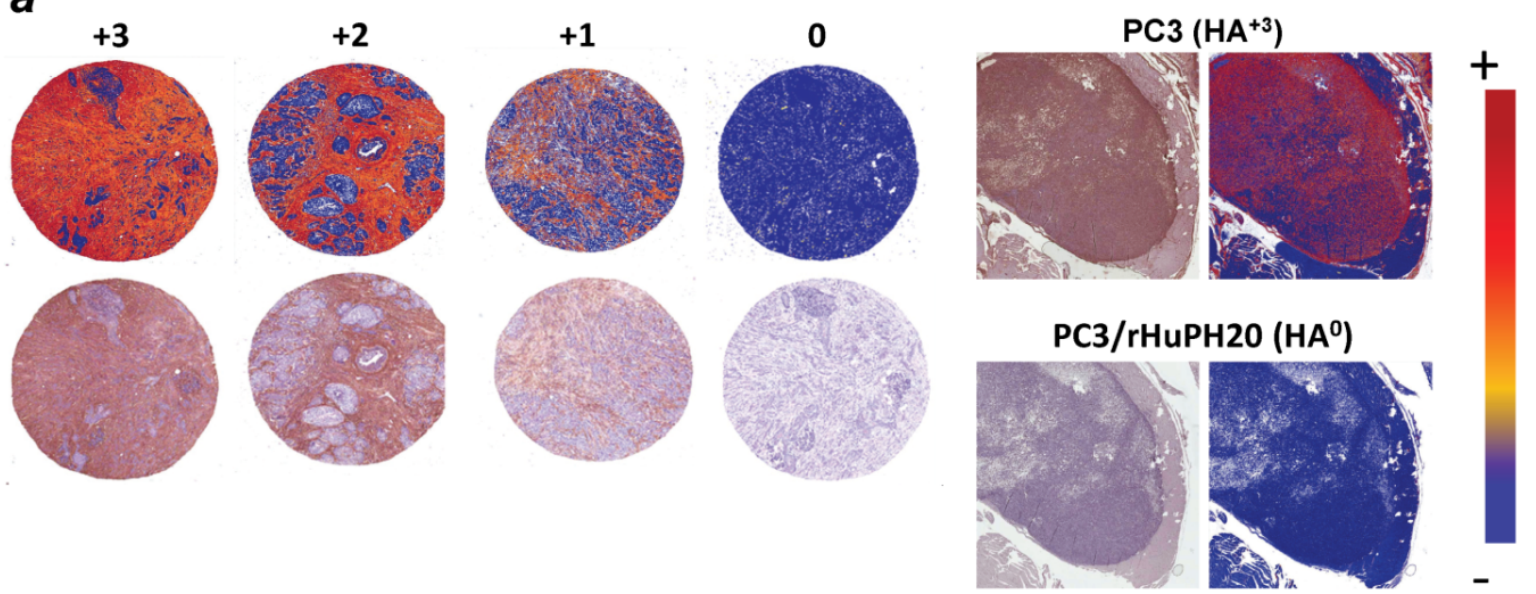
Figure 1. Cont.

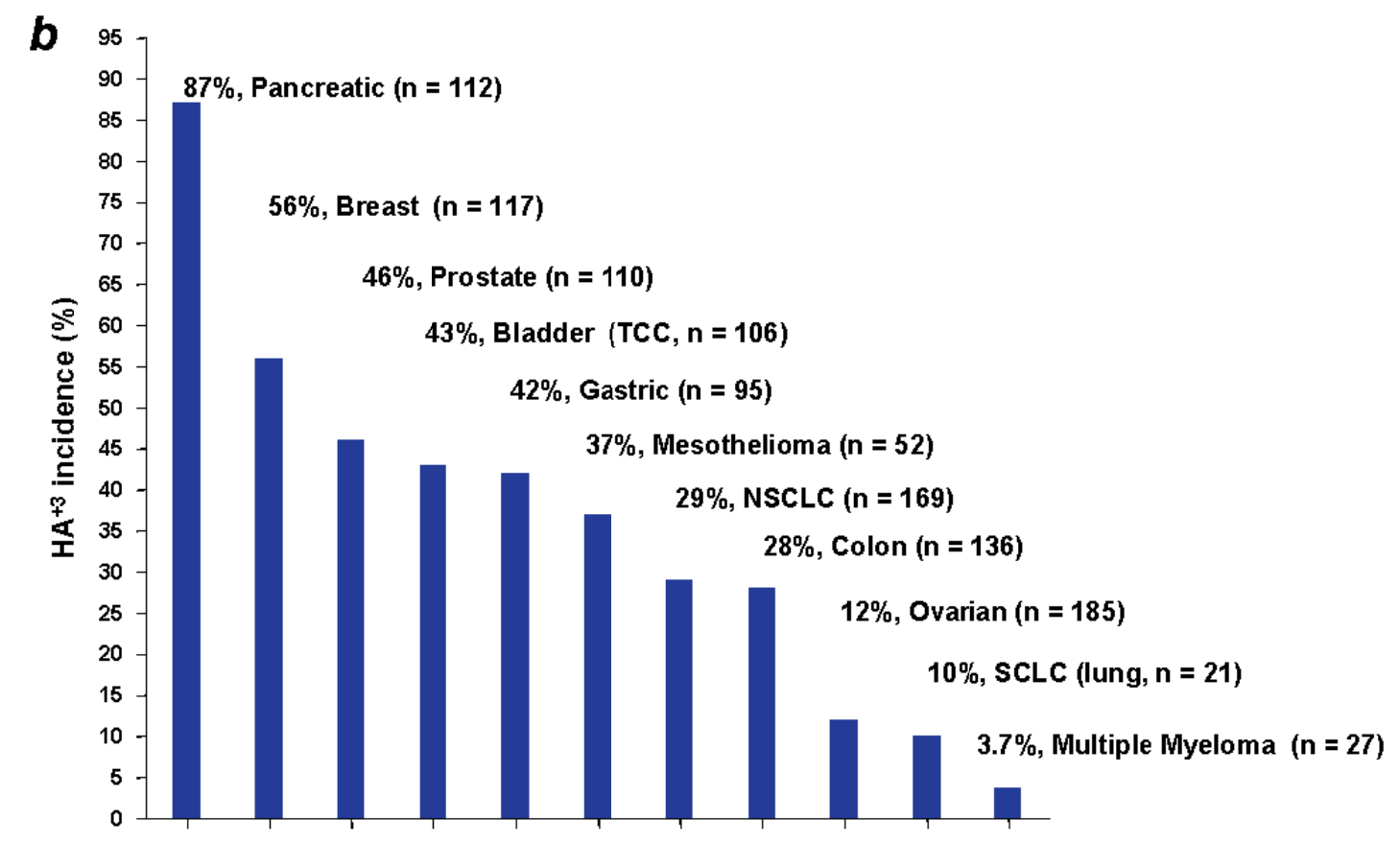

The ability of HA to imbibe water molecules coupled to its overexpression in the tumor foci contributes to the high interstitial fluid pressure observed in tumors. Indeed, high concentrations of HA in the ECM cause tissue spaces to become hydrated and to swell due to the HA-mediated increase in tissue osmotic pressure [45]. As compared to normal tissues, tumor interstitial fluid pressure (tIFP) can be elevated more than 30 -fold, resulting in compression of blood vessels, hypoxia and drug resistance [46]. While overexpression of HA alone in the absence of other cross-linking matrix proteins does not appear to be capable of causing elevated interstitial fluid pressure [47], when sequestered in the tumor stroma together with other ECM components it can significantly contribute to elevated tIFP.

High tIFP may also contribute to metastasis [48]. Several instances of malignant disease that link accumulation of HA with poor prognosis in cancer patients have been reported, and are discussed in detail below. The cross-linking of the ECM by HA not only has the potential to trap protumorigenic growth factors and cytokines, it can also physically interfere in the ability of immune cells to access malignant cells. A more simplistic, but equally intriguing explanation may be that elevated tIFP may in of itself generate a mobility signal for tumor cells to disseminate towards low pressure environments [49].

\section{The HA Interactome in Cancer}

HA binds directly to molecules collectively referred to as hyaladherins. These hyaladherins include proteins with diverse molecular functions, such as versican and CD44 [50,51]. Here, we categorize hyaladherins into two groups: (1) matrix proteoglycans and glycoproteins; and (2) cell surface receptors. A summary of all hypothetical HA molecular interactions, the HA interactome, illustrating HA's binding partners and associated downstream effectors, is presented in Figure 2. Both direct and indirect interactions as reported in the literature are shown, and it is understood that there are varying degrees of evidence to support the interactions shown in Figure 2. 
Figure 2. The HA Interactome. HA is produced at the plasma membrane of cancer cells and/or stromal cells by HAS enzymes and is extruded to the extracellular space where it forms a meshwork with its interacting molecules, the hyaladherins, playing multiple complex roles in cell adhesion, motility and proliferation. This diagram emphasizes interactions between HA and its binding molecules, and downstream secondary and tertiary interactions. Although shown as a single interactome in this figure, the indicated interactions might be cell type- and condition-dependent.

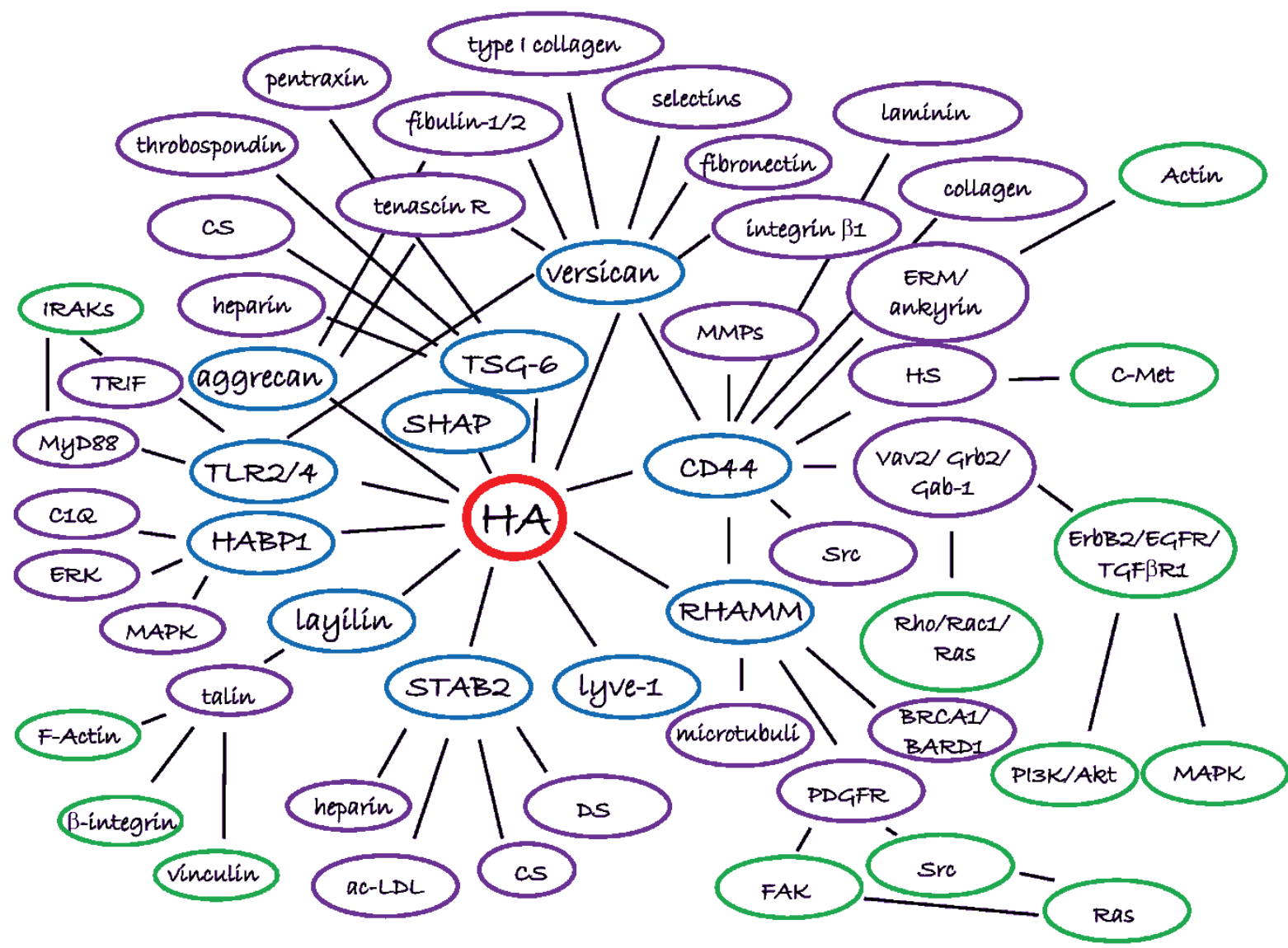

Diagram Overview: Freshly synthesized HA binds to aggregating proteoglycans, such as versican and aggrecan, and other matrix cross-linkers (tumor necrosis factor-inducible gene-6 [TSG-6], serum-associated protein-HA complex [SHAP]) that contribute to the assembly of pericellular matrix, thereby sequestering growth factors and cytokines. HA also interacts with cell surface receptors like CD44, receptor for HA-mediated motility (RHAMM) and stabilin-2 (Stab2) that anchor the HA-rich ECM to the cell surface, support its turnover, and may activate several signaling cascades. This includes the phosphoinositide 3-kinase (PI3K)-Akt and mitogen-activated protein kinase (MAPK) pathways, affecting cell survival, migration, drug resistance and epithelial-mesenchymal transformation. Conversely, some investigators have reported that fragments of HA can stimulate Toll-like receptor (TLR)-2 and TLR-4 in macrophages and induce chemokine production associated to tissue injury. CS, DS and HS are abbreviations for chondroitin sulfate, dermatan sulfate and heparan sulfate, respectively.

\subsection{HA Interactions with ECM Components}

Matrix proteoglycans and glycoproteins cross-link hydrophilic HA to the ECM, thereby having a major impact on the structure and physicochemical properties of the tissue [52]. Further, this 
"cross-linked" HA-rich matrix, in interaction with its binding partners, sequesters growth factors and cytokines in the tumor microenvironment which affects the behavior of surrounding malignant and stromal cells [43]. As an example, in PDA, which is characterized by stromal desmoplasia (the formation and development of fibrous tissue) and hypovascularity, stromal accumulation of HA and other matrix components leads to high tIFP, vascular compression and inefficient drug delivery $[11,12]$. Aggregating proteoglycans such as versican and aggrecan also have an important role in the formation of pericellular HA-rich coats in many cell types that regulate cell proliferation and migration. For instance versican, by binding to type I collagen, tenascin-R, fibulin-1, fibulin-2, fibronectin and fibrillin-1, cross-links these matrix components which facilitates tumor invasion and metastasis [53-62]. Interestingly, $\mathrm{HAS}^{-/-}$mice and heart-defect (hdf) mice lacking versican have a similar phenotype: a defect in the formation of cardiac jelly and endocardial cushions. It seems that neither HA nor versican is sufficient alone, but both components are needed for the migration and transformation of endocardial cushion cells during heart development [23,63]. The importance of the HA-versican interaction is further supported by the observation that versican-HA aggregates, but not HA alone, promote angiogenesis and stromal cell recruitment in a mouse model of breast cancer [29].

HA can also be covalently cross-linked to the ECM by SHAP and TSG-6. SHAP is composed of heavy chains of inter- $\alpha$-inhibitor (I $\alpha$ I) and forms a covalent linkage to HA. Heavy chains are transferred from chondroitin sulfate of I $\alpha$ I onto HA, with TSG-6 as a catalyst and co-factor [64,65]. Elevated SHAP-HA complex levels are found in the serum of cancer patients [66]. TSG-6 is also reported to bind to HA as oligomers, and to form complexes with pentraxin [67] and thrombospondin [68], bringing several HA molecules together.

\subsection{HA Interactions with Cell Surface Receptors}

HA also interacts with cell surface receptors, thereby anchoring the HA-rich ECM to the cell surface. Activation of these HA receptors may likewise stimulate signaling cascades, thereby affecting tumor cell survival, migration, drug resistance and epithelial-mesenchymal transformation. These functions may be mediated by HA synthesis-induced microvilli on tumor and/or stromal cells $[69,70]$. For instance, microvilli may facilitate HA-induced migration and invasion by providing new attachment sites and possible sites for ECM-degrading enzymes. The microvilli-containing lipid raft microdomains [69] may also serve as a preferred site for multidrug transporters and signaling molecules.

Indirectly, as a result of its interactions with cell surface receptors, HA appears to impact the clustering of RTKs, thereby influencing the constitutive activation of multiple growth-associated receptors [71]. Indeed, several studies have implicated HA in the activation of the human epidermal growth factor (EGF) receptor (HER) family of RTKs via interaction with the transmembrane HA receptor CD44, the major HA cell surface receptor [72]. Although the role of CD44, with its multiple isoforms, in tumor progression appears complex and is not completely understood [73,74], binding of HA clearly induces CD44 clustering and activation. Activated CD44 then directly or indirectly (via adapter proteins) interacts with RTKs and growth-associated receptors (transforming growth factor beta receptor [TGF $\beta$ R], platelet-derived growth factor receptor [PDGFR] and Erb [HER] family receptors) as well as non-receptor kinases, such Src or Ras family GTPases. This may activate downstream signaling cascades, especially the PI3K/Akt and MAPK pathways [72,75-77]. Finally, 
CD44 also interacts with actin cytoskeleton and affects cell shape and motility by binding to ankyrin [78] and ezrin/radixin/moesin (ERM) proteins [79].

Another HA cell surface receptor, RHAMM, is found in most mammalian cells and its expression is increased in tissue injury and cancer. In addition to its localization in cytoplasm and nucleus, RHAMM can be found at the cell surface, though it does not contain a membrane-spanning domain, nor does its mRNA sequence encode a signal sequence for secretion from the endoplasmic reticulum/Golgi complex. It has also been reported to attach to the plasma membrane via glycosylphosphatidylinositol (GPI) anchor, and can be shed or secreted from cells [80]. Binding of HA to RHAMM at the cell surface, or putatively in the cell cytosol, activates several signaling cascades via Src and Ras [81-83], and intracellular RHAMM can bind to microtubules of the mitotic spindle to regulate mitosis [84]. Intracellular RHAMM has also been suggested to have scaffolding functions to control the activity and targeting of extracellular signal-regulated kinase (ERK)1/2 to tubulin [85]. While bound to BRCA1, RHAMM regulates the normal development of breast epithelial cells and may influence the risk of breast cancer [86-88]. RHAMM can also bind directly to CD44 at the plasma membrane, and activate CD44 signaling through ERK1/2, potentially enhancing cancer cell migration [89], and indicating the collaboration of different receptors to activate signaling pathways.

As highlighted previously, HA is a polymer of disaccharides (D-glucuronic acid and $\mathrm{N}$-acetylglucosamine), which can vary in length from small HA oligosaccharides to 2,000-25,000 disaccharide unit polymers thought to normally dominate the ECM of tissues [24]. Accordingly, evidence has suggested that low molecular weight HA polymers of different sizes display unique, size-specific receptor binding activities in the stromal milieu (see Section 9.2) [90-95]. Small HA fragments, for instance, have been reported to interact with TLR-2 and TLR-4 in macrophages, inducing chemokine and cytokine production associated with tissue injury [90]. Small HA fragments have also been shown to enhance migration of melanoma cells in a TLR-4-dependent manner [91], and larger HA oligosaccharides induce the maturation of dendritic cells via TLR-4 [92]. Of note, versican also binds to TLR-2 and acts as an agonist for the receptor to activate tumor-infiltrating myeloid cells by increasing production of cytokines, like TNF- $\alpha$, to promote tumor metastasis [96]. Additionally, both HA fragments and low molecular weight HA $(15-40 \mathrm{kDa})$ have been shown to have the capacity to bind RHAMM directly [93-95], and investigators have reported that in fibrosarcoma cells low molecular weight HA increases adhesion via RHAMM-mediated focal adhesion kinase (FAK) and ERK1/2 signaling [93], while in endothelial cells HA fragments bind to RHAMM and stimulate tyrosine phosphorylation of p125FAK, paxillin and p42/44 ERK associated with induction of adhesion and proliferation [95].

Recent findings in the role of non-traditional hyaladherins in tumor progression have highlighted the importance of HA-receptor interactions in cancer biology. Inhibition of both layilin and Stab2 suppresses tumor metastasis in animal models [97,98], while HA binding protein 1 (HABP1) promotes motility of melanoma cells and tumor growth [99]. Furthermore, HABP1 is suggested to be a key regulator for lamellipodia formation and cancer metastasis [100]. Low levels of tumor HABP1 have been associated with longer survival rates in breast cancer patients [99].

It is clear from studies to date that disruption of HA-rich tumor stroma by depletion of this centrally active molecule has the potential to lead to a significant impact on tumor behavior by inducing a complete reorganization of the ECM and collapse of the tumor stroma. Enzymatic depletion of HA from 
tumors, using the hyaluronidase PEGPH20, remodels the tumor microenvironment by decreasing at least collagen 1 and 5 and tenascin-C content $[12,13]$ and leads to tumor growth inhibition associated with a reduction in DNA synthesis. In preclinical models, removal of HA also leads to normalized tIFP, decompression of vasculature, more efficient drug delivery, and increased survival $[11,12,14]$.

\section{Significance of HA Accumulation in Cancer and the Early History of Hyaluronidase Therapies}

Literature reports from the early 1950s have associated overproduction of HA with malignancy [101,102]. Later work [103-105] provided preliminary evidence that the spreading factor activity of hyaluronidase enhanced clinical efficacy of chemotherapy in doses up to 200,000 U/day. In addition, previous preclinical studies [106-108] have attributed chemopotentiation by hyaluronidase to a reduction in tIFP, which facilitates enhanced drug penetration into HA-depleted tumors. Increased production of HA in tumor cells, via ectopic HAS expression, has been shown to induce microvillus structures, suppress contact inhibition, and increase tumor growth rates in vivo [13,29,69,109,110]. Conversely, reduction of tumor HA levels in preclinical studies, either by addition of hyaluronidase or by inhibition of HAS activity, has been reported to reduce in vitro tumor cell proliferation, motility and invasion, and to reduce the growth of implanted tumors [13,14,21,111-115]. Similarly, inhibition of HA synthesis by 4-methylumbelliferone has been shown to inhibit cancer cell adhesion, breast cancer, and melanoma cell invasion and melanoma metastasis in vivo [116-119]. Recent work which helps to define the utility of PEGPH20 in the treatment of human cancer will be the subject of discussion later in this review.

Further exploration of the role of HA accumulation in tumor progression in patients has included clinical work with several solid and hematopoietic tumors [41,120]. In breast adenocarcinoma, five-year survival deteriorated as a function of increasing stromal HA levels; for low, moderate, and high HA levels, respectively, the five-year overall survival was 45\%,39\%, and $26 \%(p=0.002)$ and recurrence-free survival was $66 \%, 56 \%$, and $40 \%(p=0.008)$. The presence of HA-positive carcinoma cells correlated significantly with axillary lymph node positivity and poor differentiation. The five-year overall survival of patients exhibiting HA-positive carcinoma cells was significantly lower compared to patients without HA-positive carcinoma cells (54\% versus $81 \%$ respectively, $p=0.01$ ) [120].

In gastric carcinoma, the HA profile of 215 Stage I-IV gastric carcinoma patients was examined. A high proportion of HA-positive cells was found that was significantly associated with deep tumor invasion, nodal metastasis, positive lymphatic invasion, poor differentiation grade, as well as inferior prognosis in univariate survival analysis. Forty-four percent of the tumors evaluated had an HA labeling index of 30-100\% HA-positive cells [121]. In colorectal carcinomas, the cellular association of HA to overall survival and recurrence-free survival in 202 colorectal carcinoma samples was followed for a mean of 14 years. Both high HA intensity and labeling indices were frequently found and significantly associated with poorer overall survival, shorter recurrence-free survival, and elevated Dukes classification for 187 evaluable patients [122].

HA levels were studied in 309 epithelial ovarian cancers and 45 matched metastatic lesions. While in $73 \%$ (227 of 309) of the cases the fraction of HA-positive cancer cells was $<10 \%$, high stromal HA levels were significantly correlated with poor differentiation, serous histologic type, advanced stage, and large primary residual tumors [123]. Accumulation of HA is similarly reported to predict worsened 
outcomes in prostate, bladder and squamous cell carcinoma-type non-small cell lung cancers (NSCLC) [124-126]. Recent data suggest that pancreatic cancer has a high frequency of HA overexpression at about $87 \%$ (Figure 1) [11]. In other complementary studies, the expression of HA receptors CD44 and RHAMM have been found to predict more aggressive disease in hematologic neoplasias [127,128] and colon cancer [129]. Both of these receptors have been shown to be dysregulated by inactivation of the P53 tumor suppressor gene [130,131].

While early clinical investigations of hyaluronidase in cancer patients [103-105] demonstrated potential therapeutic activity, these studies were curtailed because of concerns of potential anaphylactic responses to the foreign proteins that are found in hyaluronidase products from animal sources and a remarkably short plasma half-life. In order to pursue the potential therapeutic utility of the hyaluronidases in cancer therapy, a pegylated form of recombinant human $\mathrm{PH} 20$ hyaluronidase was developed, PEGPH20. Whereas the non-pegylated recombinant human PH20 enzyme, rHuPH20, has a very short serum residence time $\left(\mathrm{t}_{1 / 2}=2.3 \mathrm{~min}\right)$, the polyethylene glycol (PEG)-modified rHuPH20 (PEGPH20) exhibited an increased in vivo half-life in mice of $\sim 270$-fold $\left(\mathrm{t}_{1 / 2}=10.3 \mathrm{~h}\right.$ ), making it well suited for subsequent studies evaluating the effect of HA removal and the subsequent stromal remodeling of HA-overexpressing tumors [14].

\section{Preclinical Proof of Concept for Therapeutic Targeting of HA in the Tumor Stroma}

Characterization of multiple tumor cell lines for HA expression, followed by examination of their response to the exogenous administration of PEGPH20 as transplanted tumors in animal models, demonstrated that tumors which express elevated levels of HA in vivo were more sensitive to the antitumor effects of PEGPH20 [13,14]. To test whether higher HA-expressing tumors are more sensitive to HA depletion, a set of NSCLC patient explants was analyzed for HA content using a semiquantitative scoring method that identified squamous cell lung cancers with $\mathrm{HA}^{+1}$ (low), $\mathrm{HA}^{+2}$ (medium), or $\mathrm{HA}^{+3}$ (high) phenotypes. Patient explants were used for this study in order to best imitate the genetic heterogeneity of tumors in situ, while hopefully maintaining some stromal elements that might be important to HA production [132] and response to PEGPH20. The results showed dramatic differences in the degree of response, depending upon the degree of tumor-associated HA (Figure 3) [13]. Tumor growth inhibition responses were $97 \%$ for $\mathrm{HA}^{+3}$ (LUM697), 44\% for $\mathrm{HA}^{+2}$ (LUM330), and 16\% for $\mathrm{HA}^{+1}$ (LUM858) NSCLC patient explants grown in nude mice. This suggests that in clinical trials testing stromal HA depletion using PEGPH20, pre-selection for an $\mathrm{HA}^{+3}$ phenotype may enhance the response rate in treated patients.

\section{Enzymatic Targeting of Tumor HA}

The exogenous administration of hyaluronidase has been shown to enzymatically degrade HA both in vitro and in vivo, removing HA pericellular matrices from cultured cancer cells $[13,14,69]$ and depleting tumor HA in preclinical animal models [11-14,111].

In studies of PC3 prostate cancer xenograft tumors, administration of a single intravenous bolus dose of PEGPH20 effectively removed HA from the tumor stroma within $2 \mathrm{~h}$ following administration, compared with tumor-bearing mice treated with vehicle alone, and the HA removal was concomitant 
with the appearance of PEGPH20 in the tumor (Figure 4). Further, following enzymatic treatment with PEGPH20, tumor HA was essentially absent for 3 days, gradually appearing by Day 10 [14].

Figure 3. Prospective testing of response to pegylated PH20 hyaluronidase (PEGPH20) as a function of HA phenotype. Squamous cell carcinoma-type NSCLC patient explants were first characterized for HA expression by HA staining [13] using biotinylated HA binding protein and subsequently grown in nude mice to test the hypothesis that the $\mathrm{HA}^{+3}$ phenotype (c) would respond more robustly to single-agent PEGPH20 than either the $\mathrm{HA}^{+2}$ (b) or $\mathrm{HA}^{+1}$ (a) phenotypes. TGI = tumor growth inhibition. Error bars in Figure $3 \mathrm{a}-\mathrm{c}$ represent SEM of averages of tumor volumes from 10 mice. Reprinted by permission [13]
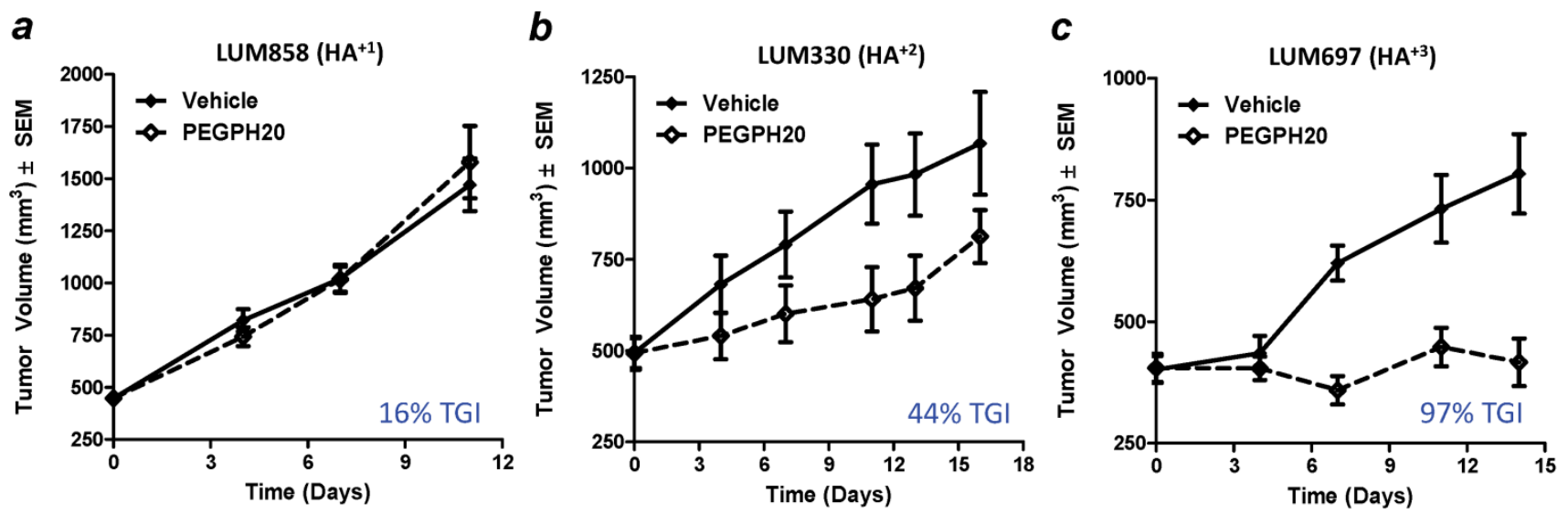

Figure 4. Impact of intravenous PEGPH20 treatment on tumor-associated HA in prostate cancer xenografts. Assessment of PEGPH20 and HA levels in PC3 xenografts harvested at 2, 8, 24, 72, and $96 \mathrm{~h}$ following intravenous administration of PEGPH20 (15 mg/kg). PEGPH20 and HA levels were assessed using an antibody to rHuPH20 and HABP, respectively. PEGPH20-mediated HA removal was sustained for $>72 \mathrm{~h}$, with a gradual return of HA signal by $\sim 10$ days (data not shown). The tissue areas selected for representation are slightly different between the anti-PH20 and HABP sections. Experimental details are given in Thompson et al. [14]. Reprinted by permission [14].
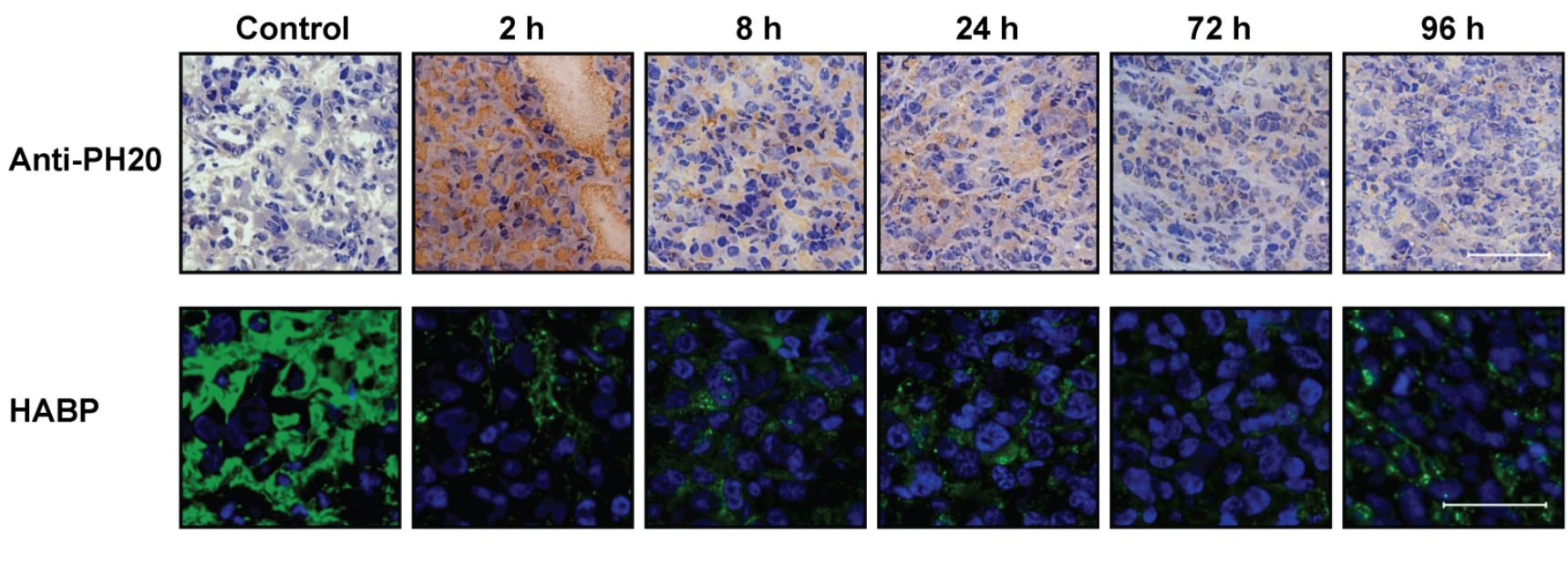

Bar $=50 \mu \mathrm{m}$ 
The degraded HA immediately has access to extracellular spaces and the circulatory system, including the lymphatics. The appearance of HA in the blood is a convenient pharmacodynamic marker for the hyaluronidase activity of PEGPH20 in animal models and patients (Figure 5), and can assist in monitoring HA degradation in vivo.

Figure 5. HA concentration in serum following in vivo treatment with PEGPH20 is a pharmacodynamic marker of hyaluronidase activity. Balb/c mice carrying 4T1 mammary tumors at volume of $\sim 400 \mathrm{~mm}^{3}$ were injected intravenously with vehicle or $10 \mu \mathrm{g} / \mathrm{kg}$ PEGPH20. Plasma was collected $24 \mathrm{~h}$ post-PEGPH20 administration and HA levels were analyzed using Hyaluronan DuoSet kit (R\&D Systems). The HA level was significantly elevated in the mice treated with PEGPH20 $(p<0.001)$. Error bars in the figure represent SEM of averages from five mice.

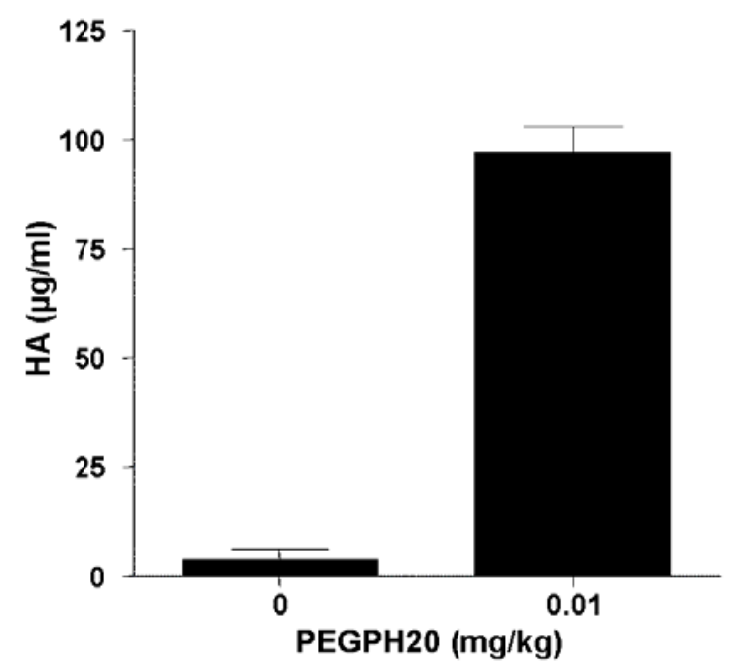

Recently, several papers have been published which shed light on the mechanism of antitumor activity mediated by the exogenous addition of PEGPH20 [11-14], and these provide additional rationale for HA-depleting reagents in the treatment of cancer. At the macrophysiological level, the hyaluronidase PEGPH20 induces massive structural changes in the tumor. These changes are translated into altered gene expression patterns. The most striking biomechanical impact of PEGPH20-mediated HA depletion from an $\mathrm{HA}^{+3}$ tumor is rapid loss of tIFP (Figure 6) [14]. Depending on dose and time, interstitial fluid pressures comparable to normal tissue can be achieved in vivo within $2 \mathrm{~h}$ of treatment. The reduction in tIFP leads to expansion of tumor blood vessels, and vascular re-perfusion [14]. Perhaps paradoxically, this increased tumor perfusion is associated with a decrease in DNA synthesis [13].

While there are numerous sequelae to these initial changes induced by PEGPH20 alone, it is now clear that these changes alone can result in inhibition of tumor cell DNA synthesis, and reduction in the expression of collagen (collagen 1-alpha-1 [Coll $\alpha 1$ ]; collagen 5-alpha-1 [Col5a1]) and tenascin-C (TNC) (Figure 7) [13], none of which directly interacts with HA. Thus, depletion of HA alone appears sufficient to induce broad remodeling of the tumor stroma. Depletion of HA, collagen and other stromal components from the ECM has raised the question of whether these changes can impact the metastatic behavior of the malignant cells resident within the stroma. 
Figure 6. Dose-dependent effect of PEGPH20 in vivo on tIFP in PC3 peritibial tumors. Mice were treated intravenously with $0-15 \mathrm{mg} / \mathrm{kg}$ PEGPH20 (doses in $\mathrm{mg} / \mathrm{kg}$ are shown on the right) and tumor IFP was measured over a $2 \mathrm{~h}$ period post-administration. Experimental details are given in Thompson et al. [14]. Reprinted by permission [14].

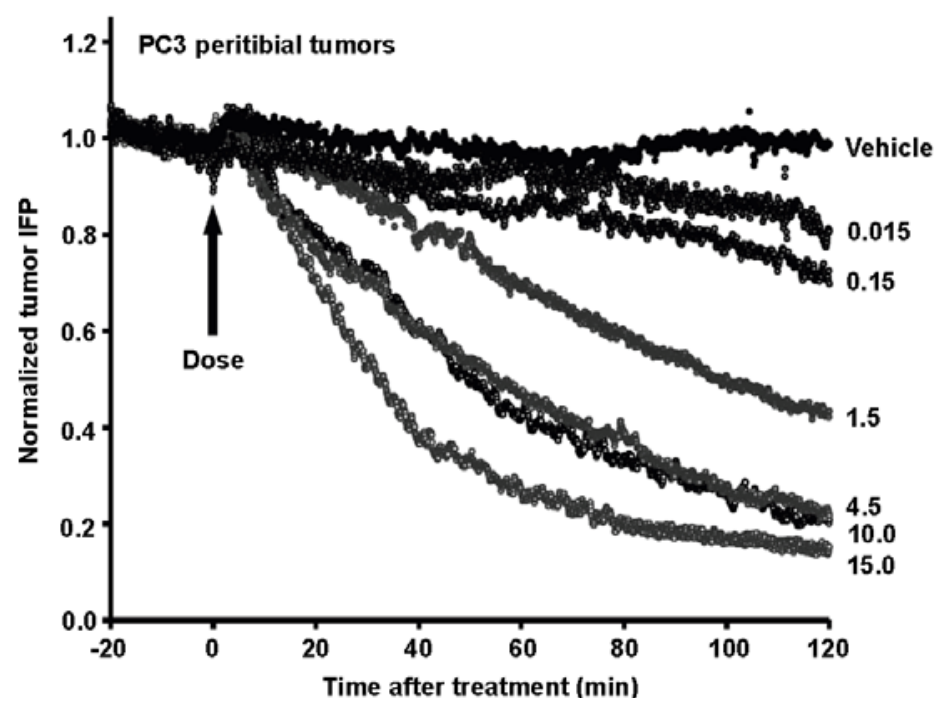

Figure 7. Depletion of HA from the ECM results in decreased DNA synthesis and molecular remodeling of the tumor. Antitumor and stromal-depleting effects are observed after treatment of PC3 $\left(\mathrm{HA}^{+3}\right)$ xenografts with PEGPH20. These include reduced tumor DNA synthesis (a); tumor-specific depletion of collagen (b); and decreased synthesis of stromal proteins (tenascin C, collagens 1 and 5) (c); Experimental details are described in Jiang et al. [13]. Error bars represent SEM of averages from six mice. Reprinted by permission [13].

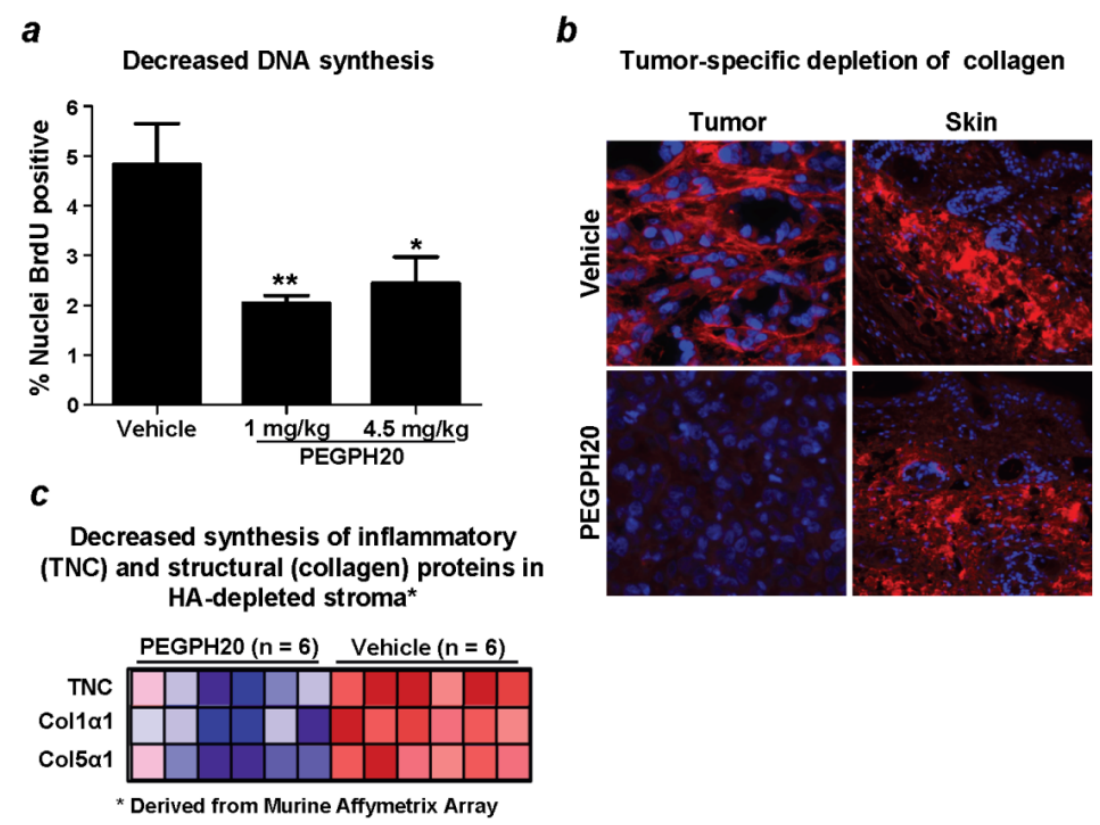

In addition to the xenograft models which provided initial proof of concept for the antitumor activity of PEGPH20, a novel model of pancreatic cancer using a genetically engineered mouse model, called the KPC (LSL-Kras ${ }^{\mathrm{G} 12 \mathrm{D} /+}$; LSL-Trp53 ${ }^{\mathrm{R} 172 \mathrm{H} /+}$; Pdx-1-Cre) mouse has recently been employed [133]. 
The advantage of this model is that it develops autochthonous tumors that appear to mimic structural aspects and clinical symptoms of human PDA [134]. PDAs that occur in this model commonly accumulate HA and express high tIFP [11,12]. Treatment of KPC tumors with PEGPH20 depletes tumors of HA, leads to the expansion of intratumoral blood vessels, and, similarly to xenograft models [11,12,14], increases delivery of chemotherapy (doxorubicin, gemcitabine) to the tumor [11]. While similar effects have been reported by other agents that target stromal targets, e.g., the hedgehog pathway [134], the mechanism by which this occurs has not been defined. In the case of PEGPH20, the rapid expansion of blood vessels as $\mathrm{HA}$ is depleted leads to ultrastructural changes in tumor endothelium, characterized in part as a significant increase in endothelial fenestrae (Figure 8) [11]. No similar changes in the non-tumor-associated endothelium are observed [11], which suggests that increased fenestrae result from the abrupt change in vessel structure once tIFP is reduced and blood vessels rapidly expand.

Figure 8. Induction of endothelial fenestrae as a result of treatment with PEGPH20. (a) The frequency of vascular fenestrae in KPC tumors was estimated using scanning electron microscopy and quantified in 4 random vessels in 3 mice per cohort; (b) Visualization of fenestrae from vehicle-treated and PEGPH20-treated KPC mice with PDA by scanning electron microscopy ( $n=4$ for each cohort). Fenestrations were found in pancreatic blood vessels of PEGPH20-treated tumors. PEGPH20 did not induce formation of fenestrae in normal pancreatic blood vessels of the control (PC) mouse. Experimental details are described in Jacobetz et al. [11]. Reprinted by permission [11].
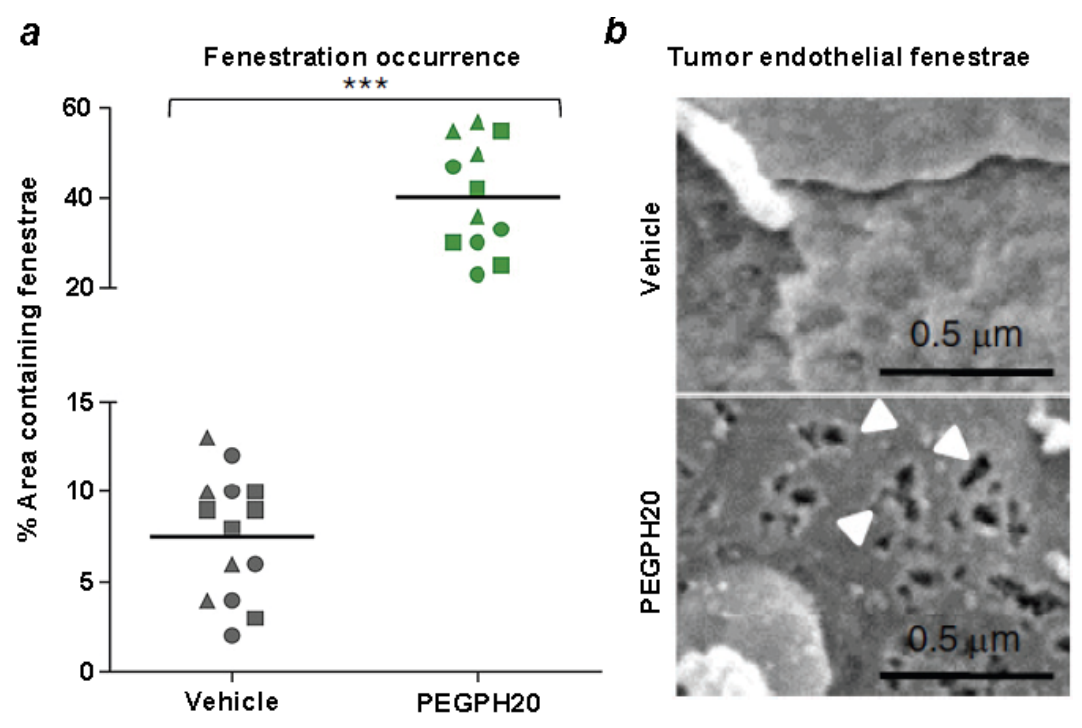

\section{Combining Therapeutic Targeting of Tumor HA with Chemotherapy}

As a single agent, hyaluronidases routinely show therapeutic efficacy in preclinical tumor xenografts that accumulate HA $[13,14,111]$. Shuster and co-workers reported that purified testicular hyaluronidase suppresses tumor growth of breast cancer xenografts [111], while removal of HA using PEGPH20 has been efficacious in mouse xenograft models of human prostate, breast, lung and pancreatic cancer and in human NSCLC explant models (see Figure 3) [11,13,14]. It is likely that this antitumor effect is related to the major structural alterations induced in the tumor (stroma, including 
vasculature) resulting from stromal remodeling, and subsequent changes in gene expression. These structural changes, especially vascular expansion and formation of fenestrae, which occur only in the impacted tumor stroma and not in normal tissues, are among the alterations observed in tumor vasculature following treatment with PEGPH20. This outcome allows for the possibility of synergistic antitumor activity of hyaluronidases and chemotherapy. Hyaluronidase has been shown to enhance antitumor activity of adriamycin and vinblastine in breast cancer and melanoma mouse models, respectively [106,135]. There are also early clinical studies reporting that co-treatment of hyaluronidase and chemotherapy or radiation therapy added efficacy of the treatment compared to monotherapy in Kaposi's sarcoma and malignant pediatric tumors [103,136]. On the other hand, in a large randomized study of high-grade astrocytomas, hyaluronidase failed to show a synergstic effect with chemotherapy or radiation therapy upon survival, which was speculated to be due to the intrinsic resistance of high grade astrocytomas to chemotherapeutic agents [104].

Enhanced activity of chemotherapy by co-treatment with PEGPH20 was initially shown in transplantable mouse tumor models [14]. Synergistic activity with the combination of PEGPH20 with chemotherapy was also observed in the transgenic mouse model (KPC) of PDA (Table 1) [11,12]. In this model, PEGPH20 administration ( $4.5 \mathrm{mg} / \mathrm{kg}$; every 3 days) had no significant effect compared to vehicle alone ( $\sim 10$ days); there was a $43 \%$ increase in survival time when animals were treated with gemcitabine (15 days) (administered 30 min post-PEGPH20), and an almost three-fold increase in survival time when animals were treated with a combination of PEGPH20 and gemcitabine (28.5 days) [11].

Table 1. Synergistic increase in survival by co-treatment of transgenic mouse model of PDA with PEGPH20 and gemcitabine [11].

\begin{tabular}{|c|c|c|c|}
\hline Treatment $^{1}$ & $\mathbf{n}$ & Median Survival (days) & Increase in Survival $^{2}(\%)$ \\
\hline Vehicle & 7 & 10.5 & 0 \\
\hline Gemcitabine & 11 & 15.0 & 43 \\
\hline PEGPH20 & 10 & 9.0 & 0 \\
\hline $\begin{array}{c}\text { Gemcitabine + } \\
\text { PEGPH20 }\end{array}$ & 11 & 28.5 & 271 \\
\hline
\end{tabular}

\section{Endogenous Hyaluronidases and HA Oligosaccharides as Tumor Promotors or Suppressors}

\subsection{Endogenous Hyaluronidase Activity}

Although there is growing evidence that exogenous hyaluronidase administration displays significant antitumor activity in HA-overexpressing tumors, local endogenous hyaluronidase expression, within the tumor milieu itself, has been shown to act as a tumor promoter. In preclinical studies, for instance, overexpression of HYAL2 has been observed to stimulate tumor growth in a mouse model of astrocytoma [137], and Tan and co-workers have reported that HYAL1 overexpression promotes tumor growth and angiogenesis in a breast cancer xenograft model [138]. In bladder and prostate cancer cells, HYAL1 seems to be the major tumor-derived hyaluronidase $[139,140]$ and inhibition of hyaluronidase activity has been shown to suppress LNCaP-AI prostate tumor growth in a xenograft mouse model [141]. 
Clinically, hyaluronidase activity has been shown to be increased in tumor tissues and/or the serum from prostate, bladder, head and neck, metastatic breast and metastatic brain cancers [140-146]. Elevated hyaluronidase activity has also been observed in urine from patients with intermediate- or high-grade bladder cancer [147], in urine from children with Wilms tumors [148], and in the saliva of patients with head and neck squamous cell carcinoma [144]. Conversely, in patients with ovarian cancer, Nykopp and colleagues reported that downregulation of HYAL1, with the concomitant decrease in hyaluronidase activity, is correlated with elevated tumor HA content [149].

Lokeshwar and Selzer suggested that whether hyaluronidase functions as a tumor promotor or suppressor might be hyaluronidase concentration dependent [150], as levels that exceed the endogenous concentrations found in tumor tissues ( 100 milliunits $/ 10^{6}$ cells) have been shown to reduce tumor growth via the induction of apoptosis $[13,14,111,151,152]$ while lower levels of hyaluronidase present in genitourinary tumors, for instance, promote tumor growth [150].

\subsection{HA Oligosaccharides in Cancer}

Both the exogenous administration of hyaluronidase and the expression of endogenous hyaluronidase within a tumor can result in the generation of HA fragments of various lengths. Lower molecular weight HA polymers and HA oligosaccharides have been reported to have biological activities not associated or opposite than ones of the high molecular weight HA [24,153,154]. Several studies have implicated that HA oligosaccharides promote angiogenesis while high molecular weight HA is anti-angiogenic $[154,155]$. Short HA oligosaccharides stimulate angiogenesis in both in vitro and in vivo chick chorioallantoic membrane assays [155], and have been shown to induce proliferation, tube formation and collagen production of endothelial cells [156-158]. Furthermore, HA fragments of 3-25 disaccharides have been reported to be present in high-grade prostate cancer tissue and in the urine of patients with highly invasive bladder cancer $[140,159]$. On the other hand, HA oligosaccharides inhibit tumor growth in xenograft models of melanoma, malignant peripheral nerve sheath tumor, ovarian cancer, lung cancer and breast cancer, as well as in mouse models of lung and bone metastasis [160-165]. Toole and co-workers have shown that HA oligosaccharides suppress the PI3K/Akt cell survival signaling pathway and reverse drug resistance in cancer cells via CD44 receptor $[165,166]$.

The physiologic effects of HA oligosaccharides likely depends on the size and local concentration of the HA fragments in the tumor [167]. Of note, there has been no evidence of new vessel formation in preclinical studies conducted with PEGPH20 [11,12]. One hypothetical explanation, in agreement with the premise that hyaluronidases function as tumor promotors or suppressors depending on local tumor hyaluronidase concentration [150], is that intravenous doses of long-acting PEGPH20 generate predominately small HA fragments which do not stimulate angiogenesis. Interestingly, Itano and Kimata have suggested that what controls the angiogenic response to HA is a balance between regulatory high molecular weight HA and effector HA oligosaccharides [43]. Ultimately, the role of HA fragments as suppressors or promoters of tumor growth seems to be a very complex phenomenon that depends upon an interplay between the tumor cells, HA receptors, associated HA binding proteins and a variety of angiogenic and other confounding factors that may be unique for every individual tumor [167]. 


\section{Therapeutic Targeting of Tumor HA and Metastasis}

Given the observations that endogenous hyaluronidase expression can act as a tumor promoter (Section 9.1), we aimed to evaluate whether the enzymatic removal of tumoral HA from HA-rich tumors promotes or inhibits metastasis using the highly metastatic human hormone-refractory prostate cancer cell line PC3 [168] which expresses high levels of HA both in vitro and in vivo [14]. First, to assess in vitro whether PEGPH20-mediated removal of extracellular HA influences the attachment (adhesion) of cells to basement membrane, potentially by exposing previously HA-hidden cell adhesion receptors such as integrins, or similarly, the invasion of cells, we used established cell adhesion [169] and Matrigel ${ }^{\mathrm{TM}}$ cell invasion assays. PEGPH20 treatment, at a concentration previously shown to completely remove all extracellular HA (1,000 U/mL) [14], reduced cell adhesion by $29 \%$ compared to vehicle alone (Figure 9a, left panel); whereas the number of PC3 cells invading downward through the Matrigel toward the chemoattractant EGF was reduced by $>50 \%$ in cells treated with PEGPH20 compared to vehicle (Figure 9a, right panel). These in vitro results indicate that HA depletion may result in anti-metastatic activity, as suggested by recent laminar flow assays which demonstrated that blockade of HA-CD44 interaction by CD44 antibody reduced tumor cell adhesion to HA in several CD44-expressing cancer cell lines [170].

Orthotopic implantation of human prostate cancer PC3 cells into nude mice was used to evaluate the effect of PEGPH20 on metastasis in vivo. This model has been shown to lead to the spontaneous formation of adjacent para-aortic lymph node (PLN) metastases [171], and is known to reproducibly generate PLN metastases in 100\% of PC3 tumor-bearing mice within 43 days [168]. Accordingly, PC3 cells expressing the enhanced green fluorescence protein (GFP) were injected into the left lobe of prostates. When tumors reached approximately $100 \mathrm{mg}$ (Day 25), the absence of PLN metastasis was confirmed in satellite animals and mice were staged into two treatment groups, vehicle control or PEGPH20. Although it is ideal to remove the primary tumor in most orthotopic spontaneous metastasis models, physical proximity of prostate tumors to the urethra and bladder makes this difficult in mice; additionally, Stephenson and colleagues [171] have previously demonstrated that orchiectomy has little effect on metastasis in this orthotopic model. Three doses of PEGPH20 (4.5 mg/kg; q3d $\times 3$ ) inhibited tumor growth of the primary tumor by $>59 \%$ within 9 days, in agreement with our earlier work which showed that higher doses of PEGPH20 reduced tumor growth in peritibially-implanted prostate PC3 cells by up to 70\% by Day 27 [14]. At study conclusion (Day 34), primary tumor and metastasis to prostate-adjacent PLNs were evaluated (Figure 9b,c). Primary tumor growth was inhibited by $>59 \%$ within 9 days (Figure $9 b$, left panel).

Metastasis occurred in 100\% (15 of 15) of vehicle-treated animals; whereas only $62.5 \%$ (10 of 16) of the PEGPH20-treated animals were positive for PLN metastatic lesions (Figure 9b, right panel; Figure 9c). Similarly, in the KPC model of PDA, combination treatment of PEGPH20 and gemcitabine decreased metastatic tumor burden compared to gemcitabine monotherapy [12]. Taken together, these studies suggest that PEGPH20-mediated HA removal, following exogenous administration, reduces metastatic incidence. This is further supported by the finding that HA fragments, similar to degradation products of PEGPH20 (Figure 5), decrease metastasis to bone in a mouse bone metastasis model of breast cancer [160]. 
Figure 9. PEGPH20 effects on metastasis. PEGPH20-mediated HA removal inhibits cell adhesion, cell invasion and reduces metastatic incidence. (a) PEGPH20-mediated in vitro pericellular HA removal reduced cell adhesion by $29 \%(p<0.001)$ compared to vehicle alone and reduced the number of PC3 cells invading downward through invasion chambers toward the chemoattractant EGF by $>50 \%$, relative to control $(p<0.001)$. Cell adhesion was evaluated as per Cos et al. [169], with modifications. Briefly, PC3 cells in culture were harvested, counted, and divided into two groups: growth medium plus $0.1 \%$ bovine serum albumin (BSA), and growth medium plus $0.1 \%$ BSA and 1,000 U/mL PEGPH20. Both suspensions were then incubated at $37{ }^{\circ} \mathrm{C}$ for $1 \mathrm{~h}$. Cells were subsequently seeded $\left(1.5 \times 10^{5}\right.$ cells/well, $\mathrm{n}=5$ wells/treatment $)$ onto Matrigel-coated plates and allowed to adhere for $1 \mathrm{~h}$ at $37^{\circ} \mathrm{C}$. At $1 \mathrm{~h}$, non-adherent cells were gently removed by washing, and attached cells were then harvested, counted, and expressed as percent relative to control cell adhesion \pm SEM. For cell invasion, PC3 cells were incubated with vehicle alone or PEGPH20 (1,000 U/mL) and seeded onto the upper chamber of invasion chambers with either vehicle buffer, or in the case of the PEGPH20-treated cells, additional PEGPH20 to prevent the re-synthesis of HA-rich pericellular matrices. The number of cells invading downward through Matrigel was expressed as percent relative to control cell invasion \pm SEM; (b) Representative images of PC3-GFP primary orthotopic tumors, and metastatic PLNs, visualized after removal of the primary tumors; (c) PEGPH20 treatment $(4.5 \mathrm{mg} / \mathrm{kg}$; $\mathrm{q} 3 \mathrm{~d} \times 3$ ), starting at Day 25 , inhibited tumor growth of the primary tumor by $>59 \%$ within 9 days (by Day 34). Further, the incidence of metastatic PLN tumors was reduced in PEGPH20-treated animals by $\sim 38 \%$, when compared to vehicle-treated animals $(100 \%$ incidence in vehicle-treated versus $62.5 \%$ incidence in PEGPH20-treated animals, respectively, $p<0.05)$.

a

PEGPH20 inhibits cell adhesion and invasion

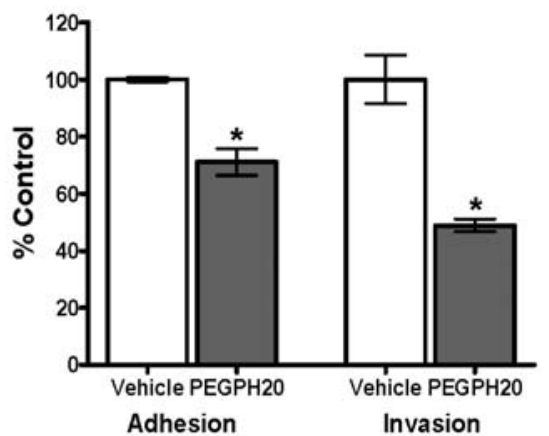

C

PEGPH20 inhibits the growth and metastasis PC3-GFP orthotopic tumors

\begin{tabular}{|c|c|c|c|c|}
\hline \multirow{2}{*}{ Group } & \multicolumn{2}{|c|}{ Tumor weight (Day 34) } & \multirow{2}{*}{$\mathrm{TGI}^{1}$} & \multirow{2}{*}{$\begin{array}{l}\text { Metastatic } \\
\text { incidence }\end{array}$} \\
\hline & Mean \pm SD $(g)$ & $p$-value & & \\
\hline Vehicle & $0.60 \pm 0.27$ & - & - & $100 \%(15 / 15)$ \\
\hline PEGPH2O & $0.32 \pm 0.11$ & $<0.001$ & $59.3 \%$ & $62.5 \%(10 / 16)$ \\
\hline \multicolumn{5}{|c|}{$\begin{array}{l}1 \text { Tumor Growth Inhibition (\%TGI) for PEGPH20 treatment groups was } \\
\text { calculated using the formula: }\left[1-\left(\mathrm{T}_{B}-\mathrm{T}_{A}\right) \div\left(\mathrm{C}_{B}-\mathrm{C}_{A}\right)\right] \times 100 \text {, where ' } \mathrm{C}_{A} \text { ' is } \\
\text { the average tumor weight in the control group at Day } 25 \text {, ' } \mathrm{C}_{B} \text { ' is the } \\
\text { average tumor weight in the control group at Day } 34, ' \mathrm{~T}_{A} \text { ' is the } \\
\text { average tumor weight }(\mathrm{mg}) \text { in the treatment group at Day } 25 \text {, and ' } \mathrm{T}_{B} \text { ' } \\
\text { is the average tumor weight }(\mathrm{mg}) \text { in the treatment group at Day } 34 \text {. }\end{array}$} \\
\hline
\end{tabular}

b

PC3-GFP orthotopic tumors \pm PEGPH20

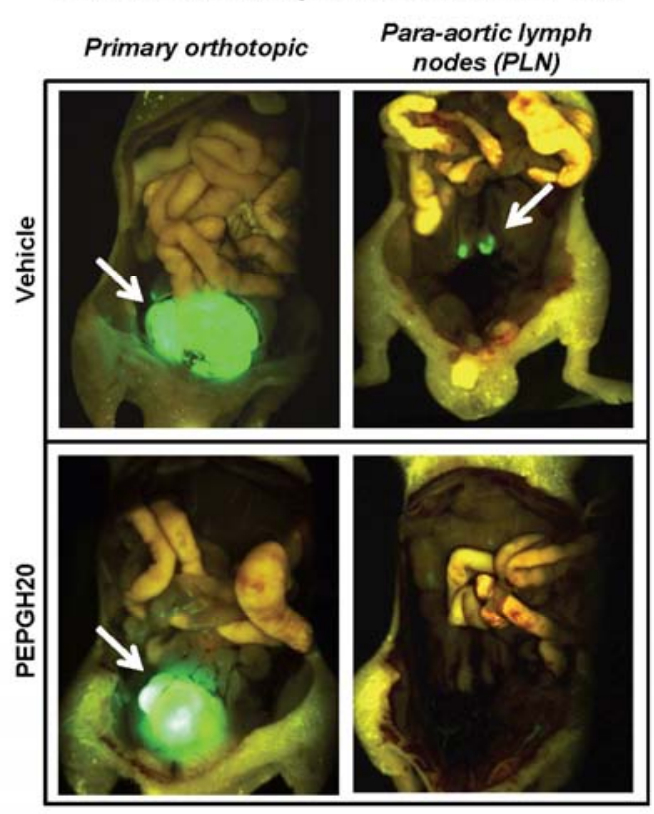




\section{Conclusions}

In recent years, with the increased recognition of the role of the tumor microenvironment in disease progression, stromal components of the tumor have emerged as attractive targets for therapeutic intervention. One such emerging target is the large glycosaminoglycan HA, a major constituent of the ECM of most tissues, and a molecule which accumulates in many solid tumors [41]. HA actively interacts with its binding molecules, the hyaladherins, which consist of ECM proteoglycans and glycoproteins, such as versican, and cell surface receptors, such as CD44 and RHAMM [29,77,80,172]. The outcome of these interactions, and the associated downstream effectors, the biological complexity of which can be graphically illustrated as a HA interactome, highlight HA's complex role in tumor cell adhesion, motility, proliferation and invasion $[26,42,43,72]$.

Accordingly, enzymatic depletion of HA can significantly impact tumor behavior by inducing a complete reorganization of the ECM, and in preclinical studies, intravenous administration of a pegylated hyaluronidase is associated with decreased tIFP, expansion of tumor blood vessels, increased delivery of chemotherapeutics, tumor growth suppression and improved survival [11-14]. The anti-tumor effects observed following the systemic administration of hyaluronidases to HA-overexpressing tumors appears to be in contrast to studies where local endogenous hyaluronidase, secreted within the tumor itself, acts predominantly as a tumor promoter [150,152]. These contradictory findings may be a hyaluronidase "concentration-dependent phenomenon", with tumor growth inhibition only observed following treatment at the pharmacological levels seen with exogenous administration [150]. Similarly, HA fragments have been shown to both suppress and stimulate tumor progression, and this likely depends on the size and local concentration of the HA fragments in the tumor (i.e., the balance between high molecular weight HA and smaller HA fragments) $[43,167]$ which can be regulated by HA synthases and/or the local tumor hyaluronidase concentration [150,167].

In the future, further knowledge about the biology of the HA interactome, as well as the tumor stroma as a whole, and, furthermore, a more complete definition of the important elements of the stroma that dictate aggressive malignancy, will enable new cancer therapies to emerge.

\section{Acknowledgments}

The authors wish to thank Ryan Osgood and Susan Zimmerman for support with the PEGPH20 metastasis studies, and Scott Patton for editing and formatting.

\section{References}

1. Sund, M.; Kalluri, R. Tumor stroma derived biomarkers in cancer. Cancer Metastasis Rev. 2009, 28, 177-183.

2. Weinberg, R.A. Coevolution in the tumor microenvironment. Nat. Genet. 2008, 40, 494-495.

3. Shimoda, M.; Mellody, K.T.; Orimo, A. Carcinoma-associated fibroblasts are a rate-limiting determinant for tumour progression. Semin. Cell Dev. Biol. 2010, 21, 19-25.

4. Johansson, A.; Ganss, R. Remodeling of tumor stroma and response to therapy. Cancers 2012, 4, $340-353$. 
5. Bissell, M.J.; Hines, W.C. Why don't we get more cancer? A proposed role of the microenvironment in restraining cancer progression. Nat. Med. 2011, 17, 320-329.

6. Shepard, H.M.; Brdlik, C.M.; Schreiber, H. Signal integration: A framework for understanding the efficacy of therapeutics targeting the human EGFR family. J. Clin. Invest. 2008, 118, 3574-3581.

7. Ferrara, N. VEGF as a therapeutic target in cancer. Oncology 2005, 69, 11-16.

8. Kelleher, F.C. Hedgehog signaling and therapeutics in pancreatic cancer. Carcinogenesis 2011, 32, 445-451.

9. Liu, Q.; Sun, J.D.; Wang, J.; Ahluwalia, D.; Baker, A.F.; Cranmer, L.D.; Ferraro, D.; Wang, Y.; Duan, J.X.; Ammons, W.S.; et al. TH-302, a hypoxia-activated prodrug with broad in vivo preclinical combination therapy efficacy: Optimization of dosing regimens and schedules. Cancer Chemother. Pharmacol. 2012, 69, 1487-1498.

10. Weiss, G.J.; Infante, J.R.; Chiorean, E.G.; Borad, M.J.; Bendell, J.C.; Molina, J.R.; Tibes, R.; Ramanathan, R.K.; Lewandowski, K.; Jones, S.F.; et al. Phase 1 study of the safety, tolerability, and pharmacokinetics of TH-302, a hypoxia-activated prodrug, in patients with advanced solid malignancies. Clin. Cancer Res. 2011, 17, 2997-3004.

11. Jacobetz, M.A.; Chan, D.S.; Neesse, A.; Bapiro, T.E.; Cook, N.; Frese, K.K.; Feig, C.; Nakagawa, T.; Caldwell, M.E.; Zecchini, H.I.; et al. Hyaluronan impairs vascular function and drug delivery in a mouse model of pancreatic cancer. Gut 2012, doi:10.1136/gutjnl-2012-302529.

12. Provenzano, P.P.; Cuevas, C.; Chang, A.E.; Goel, V.K.; von Hoff, D.D.; Hingorani, S.R. Enzymatic targeting of the stroma ablates physical barriers to treatment of pancreatic ductal adenocarcinoma. Cancer Cell 2012, 21, 418-429.

13. Jiang, P.; Li, X.; Thompson, C.B.; Huang, Z.; Araiza, F.; Osgood, R.; Wei, G.; Feldmann, M.; Frost, G.I.; Shepard, H.M. Effective targeting of the tumor microenvironment for cancer therapy. Anticancer Res. 2012, 32, 1203-1212.

14. Thompson, C.B.; Shepard, H.M.; O’Connor, P.M.; Kadhim, S.; Jiang, P.; Osgood, R.J.; Bookbinder, L.H.; Li, X.; Sugarman, B.J.; Connor, R.J.; et al. Enzymatic depletion of tumor hyaluronan induces antitumor responses in preclinical animal models. Mol. Cancer Ther. 2010, 9, 3052-3064.

15. Phase 1 Study of PEGPH20 With Initial Dexamethasone Premedication Given Intravenously to Patients With Advanced Solid Tumors (Sponsor: Halozyme Therapeutics). Available online: http://clinicaltrials.gov/ct2/show/NCT01170897?term=NCT01170897\&rank=1/ (accessed on 7 August 2012).

16. Phase $1 \mathrm{~B} / 2$ Study of Gemcitabine + PEGPH20 versus Gemcitabine Alone in Stage IV Previously Untreated Pancreatic Cancer (Sponsor: Halozyme Therapeutics). Available online: http://clinicaltrials.gov/ct2/show/NCT01453153?term=NCT01453153\&rank=1/ (accessed on 7 August 2012).

17. Weigel, P.H.; DeAngelis, P.L. Hyaluronan synthases: A decade-plus of novel glycosyltransferases. J. Biol. Chem. 2007, 282, 36777-36781.

18. Jokela, T.A.; Makkonen, K.M.; Oikari, S.; Kärnä, R.; Koli, E.; Hart, G.W.; Tammi, R.H.; Carlberg, C.; Tammi, M.I. Cellular content of UDP- $N$-acetylhexosamines controls hyaluronan synthase 2 expression and correlates with $O$-linked $N$-acetylglucosamine modification of transcription factors YY1 and SP1. J. Biol. Chem. 2011, 286, 33632-33640. 
19. Itano, N.; Sawai, T.; Yoshida, M.; Lenas, P.; Yamada, Y.; Imagawa, M.; Shinomura, T.; Hamaguchi, M.; Yoshida, Y.; Ohnuki, Y.; et al. Three isoforms of mammalian hyaluronan synthases have distinct enzymatic properties. J. Biol. Chem. 1999, 274, 25085-25092.

20. Viola, M.; Vigetti, D.; Genasetti, A.; Rizzi, M.; Karousou, E.; Moretto, P.; Clerici, M.; Bartolini, B.; Pallotti, F.; de Luca, G.; et al. Molecular control of the hyaluronan biosynthesis. Connect. Tissue Res. 2008, 49, 111-114.

21. Li, L.; Asteriou, T.; Bernert, B.; Heldin, C.H.; Heldin, P. Growth factor regulation of hyaluronan synthesis and degradation in human dermal fibroblasts: Importance of hyaluronan for the mitogenic response of PDGF-BB. Biochem. J. 2007, 404, 327-336.

22. Wilkinson, T.S.; Bressler, S.L.; Evanko, S.P.; Braun, K.R.; Wight, T.N. Overexpression of hyaluronan synthases alters vascular smooth muscle cell phenotype and promotes monocyte adhesion. J. Cell. Physiol. 2006, 206, 378-385.

23. Camenisch, T.D.; Spicer, A.P.; Brehm-Gibson, T.; Biesterfeldt, J.; Augustine, M.L.; Calabro, A., Jr.; Kubalak, S.; Klewer, S.E.; McDonald, J.A. Disruption of hyaluronan synthase-2 abrogates normal cardiac morphogenesis and hyaluronan-mediated transformation of epithelium to mesenchyme. J. Clin. Invest. 2000, 106, 349-360.

24. Tien, J.Y.; Spicer, A.P. Three vertebrate hyaluronan synthases are expressed during mouse development in distinct spatial and temporal patterns. Dev. Dyn. 2005, 233, 130-141.

25. Jokela, T. Regulation of hyaluronan synthesis by UDP-sugars. Ph.D. Thesis, University of Eastern Finland, Kuopio, Finland, 2011.

26. Toole, B.P. Hyaluronan: From extracellular glue to pericellular cue. Nat. Rev. Cancer 2004, 4, 528-539.

27. Spicer, A.P.; Tien, J.Y. Hyaluronan and morphogenesis. Birth Defects Res. C Embryo Today 2004, 72, 89-108.

28. Spicer, A.P.; Tien, J.L.; Joo, A.; Bowling, R.A., Jr. Investigation of hyaluronan function in the mouse through targeted mutagenesis. Glycoconj. J. 2002, 19, 341-345.

29. Koyama, H.; Hibi, T.; Isogai, Z.; Yoneda, M.; Fujimori, M.; Amano, J.; Kawakubo, M.; Kannagi, R.; Kimata, K.; Taniguchi, S.; et al. Hyperproduction of hyaluronan in neu-induced mammary tumor accelerates angiogenesis through stromal cell recruitment: Possible involvement of versican/PG-M. Am. J. Pathol. 2007, 170, 1086-1099.

30. Csoka, A.B.; Frost, G.I.; Stern, R. The six hyaluronidase-like genes in the human and mouse genomes. Matrix Biol. 2001, 20, 499-508.

31. Jadin, L.; Wu, X.; Ding, H.; Frost, G.I.; Onclinx, C.; Triggs-Raine, B.; Flamion, B. Skeletal and hematological anomalies in HYAL2-deficient mice: A second type of mucopolysaccharidosis IX? FASEB J. 2008, 22, 4316-4326.

32. Atmuri, V.; Martin, D.C.; Hemming, R.; Gutsol, A.; Byers, S.; Sahebjam, S.; Thliveris, J.A.; Mort, J.S.; Carmona, E.; Anderson, J.E.; et al. Hyaluronidase 3 (HYAL3) knockout mice do not display evidence of hyaluronan accumulation. Matrix Biol. 2008, 27, 653-660.

33. Martin, D.C.; Atmuri, V.; Hemming, R.J.; Farley, J.; Mort, J.S.; Byers, S.; Hombach-Klonisch, S.; Csoka, A.B.; Stern, R.; Triggs-Raine, B.L. A mouse model of human mucopolysaccharidosis IX exhibits osteoarthritis. Hum. Mol. Genet. 2008, 17, 1904-1915. 
34. Kimura, M.; Kim, E.; Kang, W.; Yamashita, M.; Saigo, M.; Yamazaki, T.; Nakanishi, T.; Kashiwabara, S.; Baba, T. Functional roles of mouse sperm hyaluronidases, HYAL5 and SPAM1, in fertilization. Biol. Reprod. 2009, 81, 939-947.

35. Triggs-Raine, B.; Salo, T.J.; Zhang, H.; Wicklow, B.A.; Natowicz, M.R. Mutations in HYAL1, a member of a tandemly distributed multigene family encoding disparate hyaluronidase activities, cause a newly described lysosomal disorder, mucopolysaccharidosis IX. Proc. Natl. Acad. Sci. USA 1999, 96, 6296-6300.

36. Baba, D.; Kashiwabara, S.; Honda, A.; Yamagata, K.; Wu, Q.; Ikawa, M.; Okabe, M.; Baba, T. Mouse sperm lacking cell surface hyaluronidase $\mathrm{PH}-20$ can pass through the layer of cumulus cells and fertilize the egg. J. Biol. Chem. 2002, 277, 30310-30314.

37. Wynne, C.; Harvey, V.; Schwabe, C.; Waaka, D.; McIntyre, C.; Bittner, B. Comparison of subcutaneous and intravenous administration of trastuzumab: A phase $\mathrm{I} / \mathrm{Ib}$ trial in healthy male volunteers and patients With HER2-positive breast cancer. J. Clin. Pharmacol. 2012, doi: $10.1177 / 0091270012436560$.

38. Frost, G.I. Recombinant human hyaluronidase (rHuPH20): An enabling platform for subcutaneous drug and fluid administration. Expert Opin. Drug Deliv. 2007, 4, 427-440.

39. Bookbinder, L.H.; Hofer, A.; Haller, M.F.; Zepeda, M.L.; Keller, G.A.; Lim, J.E.; Edgington, T.S.; Shepard, H.M.; Patton, J.S.; Frost, G.I. A recombinant human enzyme for enhanced interstitial transport of therapeutics. J. Control. Release 2006, 114, 230-241.

40. Dea, I.C.; Moorhouse, R.; Rees, D.A.; Arnott, S.; Guss, J.M.; Balazs, E.A. Hyaluronic acid: A novel, double helical molecule. Science 1973, 179, 560-562.

41. Tammi, R.H.; Kultti, A.; Kosma, V.M.; Pirinen, R.; Auvinen, P.; Tammi, M.I. Hyaluronan in human tumors: Pathobiological and prognostic messages from cell-associated and stromal hyaluronan. Semin. Cancer Biol. 2008, 18, 288-295.

42. Simpson, M.A.; Lokeshwar, V.B. Hyaluronan and hyaluronidase in genitourinary tumors. Front. Biosci. 2008, 13, 5664-5680.

43. Itano, N.; Kimata, K. Altered hyaluronan biosynthesis in cancer progression. Semin. Cancer Biol. 2008, 18, 268-274.

44. Erickson, M.; Stern, R. Chain gangs: New aspects of hyaluronan metabolism. Biochem. Res. Int. 2012, 2012, 893947:1-893947:9.

45. Meyer, F.A. Macromolecular basis of globular protein exclusion and of swelling pressure in loose connective tissue (umbilical cord). Biochim. Biophys. Acta 1983, 755, 388-399.

46. Jain, R.K. Delivery of molecular medicine to solid tumors: Lessons from in vivo imaging of gene expression and function. J. Control. Release 2001, 74, 7-25.

47. Jacobson, A.; Salnikov, A.; Lammerts, E.; Roswall, P.; Sundberg, C.; Heldin, P.; Rubin, K.; Heldin, N.E. Hyaluronan content in experimental carcinoma is not correlated to interstitial fluid pressure. Biochem. Biophys. Res. Commun. 2003, 305, 1017-1023.

48. Tse, J.M.; Cheng, G.; Tyrrell, J.A.; Wilcox-Adelman, S.A.; Boucher, Y.; Jain, R.K.; Munn, L.L. Mechanical compression drives cancer cells toward invasive phenotype. Proc. Natl. Acad. Sci. USA 2012, 109, 911-916. 
49. Wang, S.; Basson, M.D. Akt directly regulates focal adhesion kinase through association and serine phosphorylation: Implication for pressure-induced colon cancer metastasis. Am. J. Physiol. Cell Physiol. 2011, 300, C657-C670.

50. Toole, B.P. Hyaluronan and its binding proteins, the hyaladherins. Curr. Opin. Cell Biol. 1990, 2, 839-844.

51. Day, A.J. The structure and regulation of hyaluronan-binding proteins. Biochem. Soc. Trans. 1999, 27, 115-121.

52. Toole, B.P. Hyaluronan is not just a goo! J. Clin. Invest. 2000, 106, 335-336.

53. Varga, I.; Hutóczki, G.; Szemcsák, C.D.; Zahuczky, G.; Tóth, J.; Adamecz, Z.; Kenyeres, A.; Bognár, L.; Hanzély, Z.; Klekner, A. Brevican, neurocan, tenascin-C and versican are mainly responsible for the invasiveness of low-grade astrocytoma. Pathol. Oncol. Res. 2012, 18, 413-420.

54. Kodama, J.; Hasengaowa; Kusumoto, T.; Seki, N.; Matsuo, T.; Nakamura, K.; Hongo, A.; Hiramatsu, Y. Versican expression in human cervical cancer. Eur. J. Cancer 2007, 43, 1460-1466.

55. Pukkila, M.; Kosunen, A.; Ropponen, K.; Virtaniemi, J.; Kellokoski, J.; Kumpulainen, E.; Pirinen, R.; Nuutinen, J.; Johansson, R.; Kosma, V.M. High stromal versican expression predicts unfavourable outcome in oral squamous cell carcinoma. J. Clin. Pathol. 2007, 60, 267-272.

56. Said, N.; Sanchez-Carbayo, M.; Smith, S.C.; Theodorescu, D. RhoGDI2 suppresses lung metastasis in mice by reducing tumor versican expression and macrophage infiltration. J. Clin. Invest. 2012, 122, 1503-1518.

57. Wu, Y.J.; La Pierre, D.P.; Wu, J.; Yee, A.J.; Yang, B.B. The interaction of versican with its binding partners. Cell Res. 2005, 15, 483-494.

58. Aspberg, A.; Miura, R.; Bourdoulous, S.; Shimonaka, M.; Heinegârd, D.; Schachner, M.; Ruoslahti, E.; Yamaguchi, Y. The C-type lectin domains of lecticans, a family of aggregating chondroitin sulfate proteoglycans, bind tenascin-R by protein-protein interactions independent of carbohydrate moiety. Proc. Natl. Acad. Sci. USA 1997, 94, 10116-10121.

59. Aspberg, A.; Adam, S.; Kostka, G.; Timpl, R.; Heinegård, D. Fibulin-1 is a ligand for the C-type lectin domains of aggrecan and versican. J. Biol. Chem. 1999, 274, 20444-20449.

60. Olin, A.I.; Mörgelin, M.; Sasaki, T.; Timpl, R.; Heinegård, D.; Aspberg, A. The proteoglycans aggrecan and Versican form networks with fibulin-2 through their lectin domain binding. J. Biol. Chem. 2001, 276, 1253-1261.

61. Yamagata, M.; Yamada, K.M.; Yoneda, M.; Suzuki, S.; Kimata, K. Chondroitin sulfate proteoglycan (PG-M-like proteoglycan) is involved in the binding of hyaluronic acid to cellular fibronectin. J. Biol. Chem. 1986, 261, 13526-13535.

62. Isogai, Z.; Aspberg, A.; Keene, D.R.; Ono, R.N.; Reinhardt, D.P.; Sakai, L.Y. Versican interacts with fibrillin-1 and links extracellular microfibrils to other connective tissue networks. J. Biol. Chem. 2002, 277, 4565-4572.

63. Mjaatvedt, C.H.; Yamamura, H.; Capehart, A.A.; Turner, D.; Markwald, R.R. The Cspg2 gene, disrupted in the hdf mutant, is required for right cardiac chamber and endocardial cushion formation. Dev. Biol. 1998, 202, 56-66.

64. Huang, L.; Yoneda, M.; Kimata, K. A serum-derived hyaluronan-associated protein (SHAP) is the heavy chain of the inter alpha-trypsin inhibitor. J. Biol. Chem. 1993, 268, 26725-26730. 
65. Milner, C.M.; Tongsoongnoen, W.; Rugg, M.S.; Day, A.J. The molecular basis of inter-alpha-inhibitor heavy chain transfer on to hyaluronan. Biochem. Soc. Trans. 2007, 35, 672-676.

66. Yabushita, H.; Iwasaki, K.; Kanyama, K.; Obayashi, Y.; Zhuo, L.; Itano, N.; Kimata, K.; Wakatsuki, A. Clinicopathological role of serum-derived hyaluronan-associated protein (SHAP)-hyaluronan complex in endometrial cancer. Obstet. Gynecol. Int. 2011, 2011, 739150:1-739150:10.

67. Salustri, A.; Garlanda, C.; Hirsch, E.; de Acetis, M.; Maccagno, A.; Bottazzi, B.; Doni, A.; Bastone, A.; Mantovani, G.; Beck Peccoz, P.; et al. PTX3 plays a key role in the organization of the cumulus oophorus extracellular matrix and in in vivo fertilization. Development 2004, 131, 1577-1586.

68. Kuznetsova, S.A.; Day, A.J.; Mahoney, D.J.; Rugg, M.S.; Mosher, D.F.; Roberts, D.D. The $N$-terminal module of thrombospondin-1 interacts with the link domain of TSG-6 and enhances its covalent association with the heavy chains of inter-alpha-trypsin inhibitor. J. Biol. Chem. 2005, 280, 30899-30908.

69. Kultti, A.; Rilla, K.; Tiihonen, R.; Spicer, A.P.; Tammi, R.H.; Tammi, M.I. Hyaluronan synthesis induces microvillus-like cell surface protrusions. J. Biol. Chem. 2006, 281, 15821-15828.

70. Rilla, K.; Tiihonen, R.; Kultti, A.; Tammi, M.; Tammi, R. Pericellular hyaluronan coat visualized in live cells with a fluorescent probe is scaffolded by plasma membrane protrusions. J. Histochem. Cytochem. 2008, 56, 901-910.

71. Misra, S.; Toole, B.P.; Ghatak, S. Hyaluronan constitutively regulates activation of multiple receptor tyrosine kinases in epithelial and carcinoma cells. J. Biol. Chem. 2006, 281, 34936-34941.

72. Toole, B.P. Hyaluronan-CD44 interactions in cancer: Paradoxes and possibilities. Clin. Cancer Res. 2009, 15, 7462-7468.

73. Bennett, K.L.; Modrell, B.; Greenfield, B.; Bartolazzi, A.; Stamenkovic, I.; Peach, R.; Jackson, D.G.; Spring, F.; Aruffo, A. Regulation of CD44 binding to hyaluronan by glycosylation of variably spliced exons. J. Cell Biol. 1995, 131, 1623-1633.

74. Thankamony, S.P.; Knudson, W. Acylation of CD44 and its association with lipid rafts are required for receptor and hyaluronan endocytosis. J. Biol. Chem. 2006, 281, 34601-34609.

75. Bourguignon, L.Y. Hyaluronan-mediated CD44 activation of RhoGTPase signaling and cytoskeleton function promotes tumor progression. Semin. Cancer Biol. 2008, 18, 251-259.

76. Bourguignon, L.Y. Hyaluronan-Mediated CD44 Interaction with Receptor and Non-Receptor Kinases Promotes Oncogenic Signaling, Cytoskeleton Activation and Tumor Progression. In Hyaluronan in Cancer Biology, 1st ed.; Stern, R., Ed.; Academic Press/Elsevier: San Diego, CA, USA, 2009; pp. 89-107.

77. Toole, B.P.; Slomiany, M.G. Hyaluronan, CD44 and Emmprin: Partners in cancer cell chemoresistance. Drug Resist. Updat. 2008, 11, 110-121.

78. Bourguignon, L.Y.; Lokeshwar, V.B.; He, J.; Chen, X.; Bourguignon, G.J. A CD44-like endothelial cell transmembrane glycoprotein (GP116) interacts with extracellular matrix and ankyrin. Mol. Cell. Biol. 1992, 12, 4464-4471.

79. Tsukita, S.; Oishi, K.; Sato, N.; Sagara, J.; Kawai, A.; Tsukita, S. ERM family members as molecular linkers between the cell surface glycoprotein CD44 and actin-based cytoskeletons. J. Cell Biol. 1994, 126, 391-401. 
80. Maxwell, C.A.; McCarthy, J.; Turley, E. Cell-surface and mitotic-spindle RHAMM: moonlighting or dual oncogenic functions? J. Cell Sci. 2008, 121, 925-932.

81. Hall, C.L.; Wang, C.; Lange, L.A.; Turley, E.A. Hyaluronan and the hyaluronan receptor RHAMM promote focal adhesion turnover and transient tyrosine kinase activity. J. Cell Biol. 1994, 126, 575-588.

82. Hall, C.L.; Wang, F.S.; Turley, E. Src ${ }^{-/-}$fibroblasts are defective in their ability to disassemble focal adhesions in response to phorbol ester/hyaluronan treatment. Cell Commun. Adhes. 2002, 9, 273-283.

83. Itano, N.; Sawai, T.; Atsumi, F.; Miyaishi, O.; Taniguchi, S.; Kannagi, R.; Hamaguchi, M.; Kimata, K. Selective expression and functional characteristics of three mammalian hyaluronan synthases in oncogenic malignant transformation. J. Biol. Chem. 2004, 279, 18679-18687.

84. Maxwell, C.A.; Keats, J.J.; Crainie, M.; Sun, X.; Yen, T.; Shibuya, E.; Hendzel, M.; Chan, G.; Pilarski, L.M. RHAMM is a centrosomal protein that interacts with dynein and maintains spindle pole stability. Mol. Biol. Cell 2003, 14, 2262-2276.

85. Tolg, C.; Hamilton, S.R.; Morningstar, L.; Zhang, J.; Zhang, S.; Esguerra, K.V.; Telmer, P.G.; Luyt, L.G.; Harrison, R.; McCarthy, J.B.; et al. RHAMM promotes interphase microtubule instability and mitotic spindle integrity through MEK1/ERK1/2 activity. J. Biol. Chem. 2010, 285, 26461-26474.

86. Joukov, V.; Groen, A.C.; Prokhorova, T.; Gerson, R.; White, E.; Rodriguez, A.; Walter, J.C.; Livingston, D.M. The BRCA1/BARD1 heterodimer modulates ran-dependent mitotic spindle assembly. Cell 2006, 127, 539-552.

87. Maxwell, C.A.; Benítez, J.; Gómez-Baldó, L.; Osorio, A.; Bonifaci, N.; Fernández-Ramires, R.; Costes, S.V.; Guinó, E.; Chen, H.; Evans, G.J.; et al. Interplay between BRCA1 and RHAMM regulates epithelial apicobasal polarization and may influence risk of breast cancer. PLoS Biol. 2011, 9, e1001199.

88. Pujana, M.A.; Han, J.D.; Starita, L.M.; Stevens, K.N.; Tewari, M.; Ahn, J.S.; Rennert, G.; Moreno, V.; Kirchhoff, T.; Gold, B.; et al. Network modeling links breast cancer susceptibility and centrosome dysfunction. Nat. Genet. 2007, 39, 1338-1349.

89. Hamilton, S.R.; Fard, S.F.; Paiwand, F.F.; Tolg, C.; Veiseh, M.; Wang, C.; McCarthy, J.B.; Bissell, M.J.; Koropatnick, J.; Turley, E.A. The hyaluronan receptors CD44 and Rhamm (CD168) form complexes with ERK1,2 that sustain high basal motility in breast cancer cells. J. Biol. Chem. 2007, 282, 16667-16680.

90. Jiang, D.; Liang, J.; Fan, J.; Yu, S.; Chen, S.; Luo, Y.; Prestwich, G.D.; Mascarenhas, M.M.; Garg, H.G.; Quinn, D.A.; et al. Regulation of lung injury and repair by Toll-like receptors and hyaluronan. Nat. Med. 2005, 11, 1173-1179.

91. Jiang, D.; Liang, J.; Noble, P.W. Hyaluronan as an immune regulator in human diseases. Physiol. Rev. 2011, 91, 221-264.

92. Termeer, C.; Benedix, F.; Sleeman, J.; Fieber, C.; Voith, U.; Ahrens, T.; Miyake, K.; Freudenberg, M.; Galanos, C.; Simon, J.C. Oligosaccharides of Hyaluronan activate dendritic cells via toll-like receptor 4. J. Exp. Med. 2002, 195, 99-111. 
93. Kouvidi, K.; Berdiaki, A.; Nikitovic, D.; Katonis, P.; Afratis, N.; Hascall, V.C.; Karamanos, N.K.; Tzanakakis, G.N. Role of receptor for hyaluronic acid-mediated motility (RHAMM) in low molecular weight hyaluronan (LMWHA)-mediated fibrosarcoma cell adhesion. J. Biol. Chem. 2011, 286, 38509-38520.

94. Gao, F.; Yang, C.X.; Mo, W.; Liu, Y.W.; He, Y.Q. Hyaluronan oligosaccharides are potential stimulators to angiogenesis via RHAMM mediated signal pathway in wound healing. Clin. Invest. Med. 2008, 31, E106-E116.

95. Lokeshwar, V.B.; Selzer, M.G. Differences in hyaluronic acid-mediated functions and signaling in arterial, microvessel, and vein-derived human endothelial cells. J. Biol. Chem. 2000, 275, 27641-27649.

96. Wang, W.; Xu, G.L.; Jia, W.D.; Ma, J.L.; Li, J.S.; Ge, Y.S.; Ren, W.H.; Yu, J.H.; Liu, W.B. Ligation of TLR2 by versican: A link between inflammation and metastasis. Arch. Med. Res. 2009, 40, 321-323.

97. Critchley, D.R. Cytoskeletal proteins talin and vinculin in integrin-mediated adhesion. Biochem. Soc. Trans. 2004, 32, 831-836.

98. Hirose, Y.; Saijou, E.; Sugano, Y.; Takeshita, F.; Nishimura, S.; Nonaka, H.; Chen, Y.R.; Sekine, K.; Kido, T.; Nakamura, T.; et al. Inhibition of Stabilin-2 elevates circulating hyaluronic acid levels and prevents tumor metastasis. Proc. Natl. Acad. Sci. USA 2012, 109, 4263-4268.

99. Chen, Y.B.; Jiang, C.T.; Zhang, G.Q.; Wang, J.S.; Pang, D. Increased expression of hyaluronic acid binding protein 1 is correlated with poor prognosis in patients with breast cancer. J. Surg. Oncol. 2009, 100, 382-386.

100. Kim, K.B.; Yi, J.S.; Nguyen, N.; Lee, J.H.; Kwon, Y.C.; Ahn, B.Y.; Cho, H.; Kim, Y.K.; Yoo, H.J.; Lee, J.S.; et al. Cell-surface receptor for complement component $\mathrm{C} 1 \mathrm{q}(\mathrm{gC1} \mathrm{qR})$ is a key regulator for lamellipodia formation and cancer metastasis. J. Biol. Chem. 2011, 286, 23093-23101.

101. Truedsson, E. A case of mesothelioma of the pleura and peritoneum producing hyaluronic acid. Acta Soc. Med. Ups. 1951, 56, 39-45.

102. Jensen, C.E. Hyaluronic acid. IV. Isolation of hyaluronic acid from pseudomucinous ovarian cysts. Acta Pharmacol. Toxicol. (Copenh.) 1954, 10, 83-88.

103. Pillwein, K.; Fuiko, R.; Slavc, I.; Czech, T.; Hawliczek, G.; Bernhardt, G.; Nirnberger, G.; Köller, U. Hyaluronidase additional to standard chemotherapy improves outcome for children with malignant brain tumors. Cancer Lett. 1998, 131, 101-108.

104. Baumgartner, G.; Gomar-Höss, C.; Sakr, L.; Ulsperger, E.; Wogritsch, C. The impact of extracellular matrix on the chemoresistance of solid tumors - Experimental and clinical results of hyaluronidase as additive to cytostatic chemotherapy. Cancer Lett. 1998, 131, 85-99.

105. Klocker, J.; Sabitzer, H.; Raunik, W.; Wieser, S.; Schumer, J. Hyaluronidase as additive to induction chemotherapy in advanced squamous cell carcinoma of the head and neck. Cancer Lett. 1998, 131, 113-115.

106. Spruss, T.; Bernhardt, G.; Schönenberger, H.; Schiess, W. Hyaluronidase significantly enhances the efficacy of regional vinblastine chemotherapy of malignant melanoma. J. Cancer Res. Clin. Oncol. 1995, 121, 193-202.

107. Brekken, C.; de Lange Davies, C. Hyaluronidase reduces the interstitial fluid pressure in solid tumours in a non-linear concentration-dependent manner. Cancer Lett. 1998, 131, 65-70. 
108. Eikenes, L.; Tari, M.; Tufto, I.; Bruland, O.S.; de Lange Davies, C. Hyaluronidase induces a transcapillary pressure gradient and improves the distribution and uptake of liposomal doxorubicin (Caelyx) in human osteosarcoma xenografts. Br. J. Cancer 2005, 93, 81-88.

109. Kosaki, R.; Watanabe, K.; Yamaguchi, Y. Overproduction of hyaluronan by expression of the hyaluronan synthase Has2 enhances anchorage-independent growth and tumorigenicity. Cancer Res. 1999, 59, 1141-1145.

110. Koyama, H.; Kobayashi, N.; Harada, M.; Takeoka, M.; Kawai, Y.; Sano, K.; Fujimori, M.; Amano, J.; Ohhashi, T.; Kannagi, R.; et al. Significance of tumor-associated stroma in promotion of intratumoral lymphangiogenesis: Pivotal role of a hyaluronan-rich tumor microenvironment. Am. J. Pathol. 2008, 172, 179-193.

111. Shuster, S.; Frost, G.I.; Csoka, A.B.; Formby, B.; Stern, R. Hyaluronidase reduces human breast cancer xenografts in SCID mice. Int. J. Cancer 2002, 102, 192-197.

112. Simpson, M.A.; Wilson, C.M.; McCarthy, J.B. Inhibition of prostate tumor cell hyaluronan synthesis impairs subcutaneous growth and vascularization in immunocompromised mice. Am. J. Pathol. 2002, 161, 849-857.

113. Kim, H.R.; Wheeler, M.A.; Wilson, C.M.; Iida, J.; Eng, D.; Simpson, M.A.; McCarthy, J.B.; Bullard, K.M. Hyaluronan facilitates invasion of colon carcinoma cells in vitro via interaction with CD44. Cancer Res. 2004, 64, 4569-4576.

114. Nishida, Y.; Knudson, W.; Knudson, C.B.; Ishiguro, N. Antisense inhibition of hyaluronan synthase-2 in human osteosarcoma cells inhibits hyaluronan retention and tumorigenicity. Exp. Cell Res. 2005, 307, 194-203.

115. Udabage, L.; Brownlee, G.R.; Nilsson, S.K.; Brown, T.J. The over-expression of HAS2, Hyal-2 and CD44 is implicated in the invasiveness of breast cancer. Exp. Cell Res. 2005, 310, 205-217.

116. Kudo, D.; Kon, A.; Yoshihara, S.; Kakizaki, I.; Sasaki, M.; Endo, M.; Takagaki, K. Effect of a hyaluronan synthase suppressor, 4-methylumbelliferone, on B16F-10 melanoma cell adhesion and locomotion. Biochem. Biophys. Res. Commun. 2004, 321, 783-787.

117. Urakawa, H.; Nishida, Y.; Wasa, J.; Arai, E.; Zhuo, L.; Kimata, K.; Kozawa, E.; Futamura, N.; Ishiguro, N. Inhibition of hyaluronan synthesis in breast cancer cells by 4-methylumbelliferone suppresses tumorigenicity in vitro and metastatic lesions of bone in vivo. Int. J. Cancer 2012 , 130, 454-466.

118. Kultti, A.; Pasonen-Seppänen, S.; Jauhiainen, M.; Rilla, K.J.; Kärnä, R.; Pyöriä, E.; Tammi, R.H.; Tammi, M.I. 4-Methylumbelliferone inhibits hyaluronan synthesis by depletion of cellular UDP-glucuronic acid and downregulation of hyaluronan synthase 2 and 3. Exp. Cell Res. 2009, 315, 1914-1923.

119. Yoshihara, S.; Kon, A.; Kudo, D.; Nakazawa, H.; Kakizaki, I.; Sasaki, M.; Endo, M.; Takagaki, K. A hyaluronan synthase suppressor, 4-methylumbelliferone, inhibits liver metastasis of melanoma cells. FEBS Lett. 2005, 579, 2722-2726.

120. Auvinen, P.; Tammi, R.; Parkkinen, J.; Tammi, M.; Agren, U.; Johansson, R.; Hirvikoski, P.; Eskelinen, M.; Kosma, V.M. Hyaluronan in peritumoral stroma and malignant cells associates with breast cancer spreading and predicts survival. Am. J. Pathol. 2000, 156, 529-536. 
121. Setälä, L.P.; Tammi, M.I.; Tammi, R.H.; Eskelinen, M.J.; Lipponen, P.K.; Agren, U.M.; Parkkinen, J.; Alhava, E.M.; Kosma, V.M. Hyaluronan expression in gastric cancer cells is associated with local and nodal spread and reduced survival rate. Br. J. Cancer 1999, 79, 1133-1138.

122. Ropponen, K.; Tammi, M.; Parkkinen, J.; Eskelinen, M.; Tammi, R.; Lipponen, P.; Agren, U.; Alhava, E.; Kosma, V.M. Tumor cell-associated hyaluronan as an unfavorable prognostic factor in colorectal cancer. Cancer Res. 1998, 58, 342-347.

123. Anttila, M.A.; Tammi, R.H.; Tammi, M.I.; Syrjänen, K.J.; Saarikoski, S.V.; Kosma, V.M. High levels of stromal hyaluronan predict poor disease outcome in epithelial ovarian cancer. Cancer Res. 2000, 60, 150-155.

124. Josefsson, A.; Adamo, H.; Hammarsten, P.; Granfors, T.; Stattin, P.; Egevad, L.; Laurent, A.E.; Wikström, P.; Bergh, A. Prostate cancer increases hyaluronan in surrounding nonmalignant stroma, and this response is associated with tumor growth and an unfavorable outcome. Am. J. Pathol. 2011, 179, 1961-1968.

125. Kramer, M.W.; Escudero, D.O.; Lokeshwar, S.D.; Golshani, R.; Ekwenna, O.O.; Acosta, K.; Merseburger, A.S.; Soloway, M.; Lokeshwar, V.B. Association of hyaluronic acid family members (HAS1, HAS2, and HYAL-1) with bladder cancer diagnosis and prognosis. Cancer 2011, 117, 1197-1209.

126. Pirinen, R.; Tammi, R.; Tammi, M.; Hirvikoski, P.; Parkkinen, J.J.; Johansson, R.; Böhm, J.; Hollmén, S.; Kosma, V.M. Prognostic value of hyaluronan expression in non-small-cell lung cancer: Increased stromal expression indicates unfavorable outcome in patients with adenocarcinoma. Int. J. Cancer 2001, 95, 12-17.

127. Hertweck, M.K.; Erdfelder, F.; Kreuzer, K.A. CD44 in hematological neoplasias. Ann. Hematol. 2011, 90, 493-508.

128. Tzankov, A.; Strasser, U.; Dirnhofer, S.; Menter, T.; Arber, C.; Jotterand, M.; Rovo, A.; Tichelli, A.; Stauder, R.; Günthert, U. In situ RHAMM protein expression in acute myeloid leukemia blasts suggests poor overall survival. Ann. Hematol. 2011, 90, 901-909.

129. Lugli, A.; Zlobec, I.; Günthert, U.; Minoo, P.; Baker, K.; Tornillo, L.; Terracciano, L.; Jass, J.R. Overexpression of the receptor for hyaluronic acid mediated motility is an independent adverse prognostic factor in colorectal cancer. Mod. Pathol. 2006, 19, 1302-1309.

130. Godar, S.; Ince, T.A.; Bell, G.W.; Feldser, D.; Donaher, J.L.; Bergh, J.; Liu, A.; Miu, K.; Watnick, R.S.; Reinhardt, F.; et al. Growth-inhibitory and tumor- suppressive functions of p53 depend on its repression of CD44 expression. Cell 2008, 134, 62-73.

131. Sohr, S.; Engeland, K. RHAMM is differentially expressed in the cell cycle and downregulated by the tumor suppressor p53. Cell Cycle 2008, 7, 3448-3460.

132. Willenberg, A.; Saalbach, A.; Simon, J.C.; Anderegg, U. Melanoma cells control HA synthesis in peritumoral fibroblasts via PDGF-AA and PDGF-CC: Impact on melanoma cell proliferation. J. Invest. Dermatol. 2012, 132, 385-393.

133. Hingorani, S.R.; Wang, L.; Multani, A.S.; Combs, C.; Deramaudt, T.B.; Hruban, R.H.; Rustgi, A.K.; Chang, S.; Tuveson, D.A. Trp53R172H and KrasG12D cooperate to promote chromosomal instability and widely metastatic pancreatic ductal adenocarcinoma in mice. Cancer Cell 2005, 7, 469-483. 
134. Olive, K.P.; Jacobetz, M.A.; Davidson, C.J.; Gopinathan, A.; McIntyre, D.; Honess, D.; Madhu, B.; Goldgraben, M.A.; Caldwell, M.E.; Allard, D.; et al. Inhibition of Hedgehog signaling enhances delivery of chemotherapy in a mouse model of pancreatic cancer. Science 2009, 324, 1457-1461.

135. Beckenlehner, K.; Bannke, S.; Spruss, T.; Bernhardt, G.; Schönenberg, H.; Schiess, W. Hyaluronidase enhances the activity of adriamycin in breast cancer models in vitro and in vivo. J. Cancer Res. Clin. Oncol. 1992, 118, 591-596.

136. Smith, K.J.; Skelton, H.G.; Turiansky, G.; Wagner, K.F. Hyaluronidase enhances the therapeutic effect of vinblastine in intralesional treatment of Kaposi's sarcoma. Military Medical Consortium for the Advancement of Retroviral Research (MMCARR). J. Am. Acad. Dermatol. 1997, 36, 239-242.

137. Novak, U.; Stylli, S.S.; Kaye, A.H.; Lepperdinger, G. Hyaluronidase-2 overexpression accelerates intracerebral but not subcutaneous tumor formation of murine astrocytoma cells. Cancer Res. 1999, 59, 6246-6250.

138. Tan, J.X.; Wang, X.Y.; Li, H.Y.; Su, X.L.; Wang, L.; Ran, L.; Zheng, K.; Ren, G.S. HYAL1 overexpression is correlated with the malignant behavior of human breast cancer. Int. J. Cancer 2011, 128, 1303-1315.

139. Lokeshwar, V.B.; Young, M.J.; Goudarzi, G.; Iida, N.; Yudin, A.I.; Cherr, G.N.; Selzer, M.G. Identification of bladder tumor-derived hyaluronidase: Its similarity to HYAL1. Cancer Res. 1999, 59, 4464-4470.

140. Lokeshwar, V.B.; Rubinowicz, D.; Schroeder, G.L.; Forgacs, E.; Minna, J.D.; Block, N.L.; Nadji, M.; Lokeshwar, B.L. Stromal and epithelial expression of tumor markers hyaluronic acid and HYAL1 hyaluronidase in prostate cancer. J. Biol. Chem. 2001, 276, 11922-11932.

141. Benitez, A.; Yates, T.J.; Lopez, L.E.; Cerwinka, W.H.; Bakkar, A.; Lokeshwar, V.B. Targeting hyaluronidase for cancer therapy: Antitumor activity of sulfated hyaluronic acid in prostate cancer cells. Cancer Res. 2011, 71, 4085-4095.

142. Lokeshwar, V.B.; Lokeshwar, B.L.; Pham, H.T.; Block, N.L. Association of elevated levels of hyaluronidase, a matrix-degrading enzyme, with prostate cancer progression. Cancer Res. 1996, 56, 651-657.

143. Droller, M.J. Tumor-derived hyaluronidase: A diagnostic urine marker for high-grade bladder cancer. J. Urol. 1998, 160, 619-620.

144. Franzmann, E.J.; Schroeder, G.L.; Goodwin, W.J.; Weed, D.T.; Fisher, P.; Lokeshwar, V.B. Expression of tumor markers hyaluronic acid and hyaluronidase (HYAL1) in head and neck tumors. Int. J. Cancer 2003, 106, 438-445.

145. Bertrand, P.; Girard, N.; Duval, C.; d'Anjou, J.; Chauzy, C.; Ménard, J.F.; Delpech, B. Increased hyaluronidase levels in breast tumor metastases. Int. J. Cancer 1997, 73, 327-331.

146. Delpech, B.; Laquerriere, A.; Maingonnat, C.; Bertrand, P.; Freger, P. Hyaluronidase is more elevated in human brain metastases than in primary brain tumours. Anticancer Res. 2002, 22, 2423-2427.

147. Pham, H.T.; Block, N.L.; Lokeshwar, V.B. Tumor-derived hyaluronidase: A diagnostic urine marker for high-grade bladder cancer. Cancer Res. 1997, 57, 778-783.

148. Stern, M.; Longaker, M.T.; Adzick, N.S.; Harrison, M.R.; Stern, R. Hyaluronidase levels in urine from Wilms' tumor patients. J. Natl. Cancer Inst. 1991, 83, 1569-1574. 
149. Nykopp, T.K.; Rilla, K.; Sironen, R.; Tammi, M.I.; Tammi, R.H.; Hämäläinen, K.; Heikkinen, A.M.; Komulainen, M.; Kosma, V.M.; Anttila, M. Expression of hyaluronan synthases (HAS1-3) and hyaluronidases (HYAL1-2) in serous ovarian carcinomas: Inverse correlation between HYAL1 and hyaluronan content. BMC Cancer 2009, 9, 143.

150. Lokeshwar, V.B.; Selzer, M.G. Hyaluronidase: Both a tumor promoter and suppressor. Semin. Cancer Biol. 2008, 18, 281-287.

151. Jacobson, A.; Rahmanian, M.; Rubin, K.; Heldin, P. Expression of hyaluronan synthase 2 or hyaluronidase 1 differentially affect the growth rate of transplantable colon carcinoma cell tumors. Int. J. Cancer 2002, 102, 212-219.

152. Lokeshwar, V.B.; Cerwinka, W.H.; Isoyama, T.; Lokeshwar, B.L. HYAL1 hyaluronidase in prostate cancer: A tumor promoter and suppressor. Cancer Res. 2005, 65, 7782-7789.

153. Camenisch, T.D.; McDonald, J.A. Hyaluronan: Is bigger better? Am. J. Respir. Cell Mol. Biol. 2000, 23, 431-433.

154. Deed, R.; Rooney, P.; Kumar, P.; Norton, J.D.; Smith, J.; Freemont, A.J.; Kumar, S. Early-response gene signalling is induced by angiogenic oligosaccharides of hyaluronan in endothelial cells. Inhibition by non-angiogenic, high-molecular-weight hyaluronan. Int. J. Cancer 1997, 71, 251-256.

155. Rooney, P.; Kumar, S.; Ponting, J.; Wang, M. The role of hyaluronan in tumour neovascularization (review). Int. J. Cancer 1995, 60, 632-636.

156. Matou-Nasri, S.; Gaffney, J.; Kumar, S.; Slevin, M. Oligosaccharides of hyaluronan induce angiogenesis through distinct CD44 and RHAMM-mediated signalling pathways involving Cdc2 and gamma-adducin. Int. J. Oncol. 2009, 35, 761-773.

157. Rahmanian, M.; Pertoft, H.; Kanda, S.; Christofferson, R.; Claesson-Welsh, L.; Heldin, P. Hyaluronan oligosaccharides induce tube formation of a brain endothelial cell line in vitro. Exp. Cell Res. 1997, 237, 223-230.

158. Rooney, P.; Wang, M.; Kumar, P.; Kumar, S. Angiogenic oligosaccharides of hyaluronan enhance the production of collagens by endothelial cells. J. Cell Sci. 1993, 105, 213-218.

159. Lokeshwar, V.B.; Obek, C.; Soloway, M.S.; Block, N.L. Tumor-associated hyaluronic acid: A new sensitive and specific urine marker for bladder cancer. Cancer Res. 1997, 57, 773-777.

160. Urakawa, H.; Nishida, Y.; Knudson, W.; Knudson, C.B.; Arai, E.; Kozawa, E.; Futamura, N.; Wasa, J.; Ishiguro, N. Therapeutic potential of hyaluronan oligosaccharides for bone metastasis of breast cancer. J. Orthop. Res. 2012, 30, 662-672.

161. Zeng, C.; Toole, B.P.; Kinney, S.D.; Kuo, J.W.; Stamenkovic, I. Inhibition of tumor growth in vivo by hyaluronan oligomers. Int. J. Cancer 1998, 77, 396-401.

162. Slomiany, M.G.; Dai, L.; Tolliver, L.B.; Grass, G.D.; Zeng, Y.; Toole, B.P. Inhibition of functional hyaluronan-CD44 interactions in CD133-positive primary human ovarian carcinoma cells by small hyaluronan oligosaccharides. Clin. Cancer Res. 2009, 15, 7593-7601.

163. Hosono, K.; Nishida, Y.; Knudson, W.; Knudson, C.B.; Naruse, T.; Suzuki, Y.; Ishiguro, N. Hyaluronan oligosaccharides inhibit tumorigenicity of osteosarcoma cell lines MG-63 and LM-8 in vitro and in vivo via perturbation of hyaluronan-rich pericellular matrix of the cells. Am. J. Pathol. 2007, 171, 274-286. 
164. Slomiany, M.G.; Dai, L.; Bomar, P.A.; Knackstedt, T.J.; Kranc, D.A.; Tolliver, L.; Maria, B.L.; Toole, B.P. Abrogating drug resistance in malignant peripheral nerve sheath tumors by disrupting hyaluronan-CD44 interactions with small hyaluronan oligosaccharides. Cancer Res. 2009, 69, 4992-4998.

165. Ghatak, S.; Misra, S.; Toole, B.P. Hyaluronan oligosaccharides inhibit anchorage-independent growth of tumor cells by suppressing the phosphoinositide 3-kinase/Akt cell survival pathway. J. Biol. Chem. 2002, 277, 38013-38020.

166. Misra, S.; Ghatak, S.; Zoltan-Jones, A.; Toole, B.P. Regulation of multidrug resistance in cancer cells by hyaluronan. J. Biol. Chem. 2003, 278, 25285-25288.

167. Stern, R.; Asari, A.A.; Sugahara, K.N. Hyaluronan fragments: An information-rich system. Eur. J. Cell Biol. 2006, 85, 699-715.

168. Rembrink, K.; Romijn, J.C.; van der Kwast, T.H.; Rübben, H.; Schröder, F.H. Orthotopic implantation of human prostate cancer cell lines: A clinically relevant animal model for metastatic prostate cancer. Prostate 1997, 31, 168-174.

169. Cos, S.; Fernández, R.; Güézmes, A.; Sánchez-Barceló, E.J. Influence of melatonin on invasive and metastatic properties of MCF-7 human breast cancer cells. Cancer Res. 1998, 58, 4383-4390.

170. Richter, U.; Wicklein, D.; Geleff, S.; Schumacher, U. The interaction between CD44 on tumour cells and hyaluronan under physiologic flow conditions: Implications for metastasis formation. Histochem. Cell Biol. 2012, 137, 687-695.

171. Stephenson, R.A.; Dinney, C.P.; Gohji, K.; Ordóñez, N.G.; Killion, J.J.; Fidler, I.J. Metastatic model for human prostate cancer using orthotopic implantation in nude mice. J. Natl. Cancer Inst. 1992, 17, 951-957.

172. Veiseh, M.; Turley, E.A. Hyaluronan metabolism in remodeling extracellular matrix: Probes for imaging and therapy of breast cancer. Integr. Biol. (Camb.) 2011, 4, 304-315.

(C) 2012 by the authors; licensee MDPI, Basel, Switzerland. This article is an open access article distributed under the terms and conditions of the Creative Commons Attribution license (http://creativecommons.org/licenses/by/3.0/). 